\title{
TEXTURES IN NON-METALLIC MATERIALS
}

H. J. BUNGE

Department of Physical Metallurgy

Technical University of Clausthal FRG

\begin{abstract}
The texture of a polycrystalline material is defined by the orientation distribution function (ODF) of its crystallites. Besides this, the misorientation distribution MODF of neighbouring crystals may be important. Although this applies equally to all crystalline materials, texture studies have extensively been done in metals and not so much in ceramics and polymers. This is partly due to experimental difficulties of texture measurement in these materials which have only recently been overcome. Besides this, two deviating definitions of the term "texture" are being used. These are the "shape texture" in ceramics and the "chain texture" in polymers.

Textures in ceramics were studied quantitatively mainly in hard magnetic materials. They are, however, also most important in $H T_{c}$-superconductors, in ferroelectrics, in transformation toughened ceramics, in ceramic surface layers, copperbonded $\mathrm{Al}_{2} \mathrm{O}_{3}$ substrates and probably in many others. Textures in the crystalline part of polymers have been studied quantitatively using ODF-methods. "Momenta" of the orientation distribution function of the crystalline as well as the non-crystalline part can, however, be obtained more easily by physical methods. This is sufficient if the correlation between preferred orientation and anisotropic properties is considered. Texture formation by deformation is, however, related to the complete orientation distribution function.
\end{abstract}

\section{INTRODUCTION}

The term "texture" originally designates the arrangement of filaments in a woven tissue i.e. a non-metallic material. Fig. 1 shows four tissues with four different textures. Also the arrangement of 

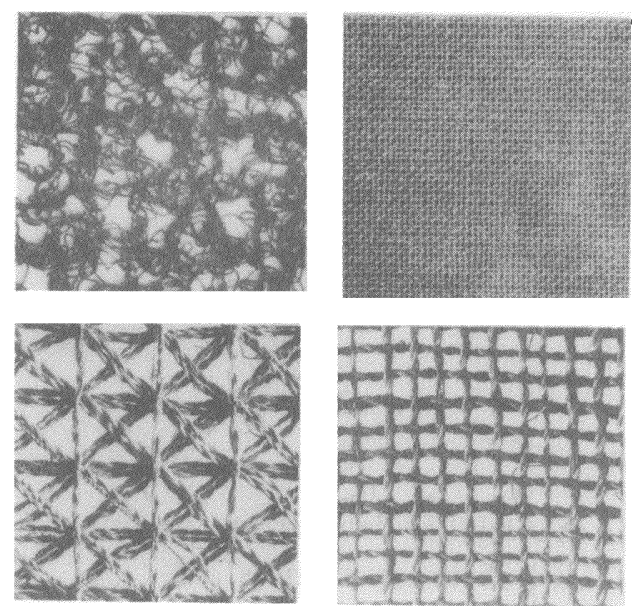

Fig.1 Woven tissues with four different textures.

Fig.2
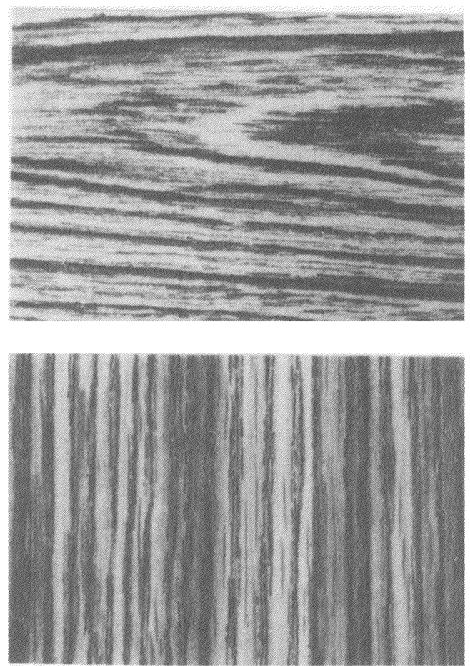

Two pieces of wood with different textures.

Fig.3 A match cut parallel to the fibres.
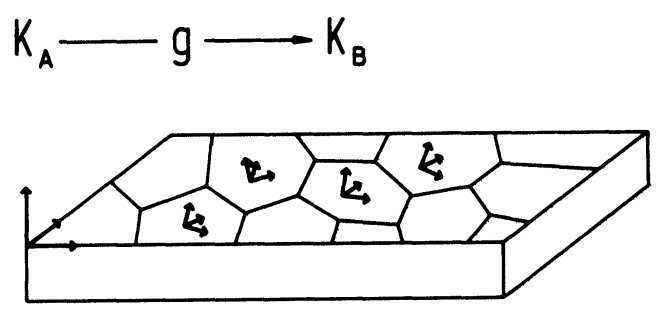

Fig.4 The texture of a polycrystalline material is defined by the orientation distribution function of the crystalites. The orientation of an individual crystalite is described by the rotation $\mathrm{g}$ which relates the crystal coordinate system $K_{B}$ to the sample coordinate system $K_{A}$. 
the fibres of wood is called "texture". Fig.2 shows the textures of two pieces of wood. The textures of these materials are responsible for the differences of mechanical properties in different directions i.e. the anisotropy of properties. Fig. 3 shows a match which must be cut parallel to the fibres, otherwise it would break immediately.

Lateron, the same term "texture" was also used for the internal structure of organic fibres which is strongly anisotropic, too. The molecular chains in such fibres often have a preferred orientation parallel to the fibre axis which shows up, for instance, in X-ray diffraction photographs. It was then only a small step to applying the same term "texture" also to drawn metal wires, the diffraction photographs of which bear some similarity to the anisotropic diagrams of polymer fibres.

In metal wires, the texture describes the orientation distribution of crystallites. This same definition was then completely generalised to the orientation distribution of crystallites of metals of any kind (not only wires) and finally to the orientation distribution of crystallites in any polycrystalline material.

\section{TEXTURES IN CRYSTALLINE MA- TERIALS}

The texture of a polycrystalline material is defined by the orientation distribution function (ODF) of its crystallites. This is shown schematically in Fig.4. In order to define the crystallographic orientation of an individual crystallite (or grain) a crystal coordinate system $K_{B}$ has to be specified (e.g. given by the crystallographic axes [100] [010] [001] in the cubic case). Another coordinate system $K_{A}$ is related to the external shape of the sample (e.g. rolling, transverse and normal direction in rolled sheet). The crystal coordinate system $K_{B}$ is related to the sample coordinate system $K_{A}$ by the rotation $g$ which thus specifies the orientation of the considered crystal

$$
K_{B}=g \cdot K_{A}
$$

The orientation $g$ may be specified in many different ways, two of which are shown in Fig.5. The crystallographic directions parallel to 
H.J. BUNGE

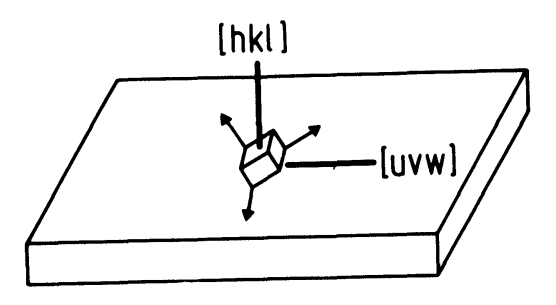

Fig.5 Two particular specifications of crystal orientation $\mathrm{g}$.

a) Ideal orientation ( $\mathrm{hkl}$ ) [uvw].

b) Eulerian angles $\left\{\varphi_{1}, \Phi, \varphi_{2}\right\}$.
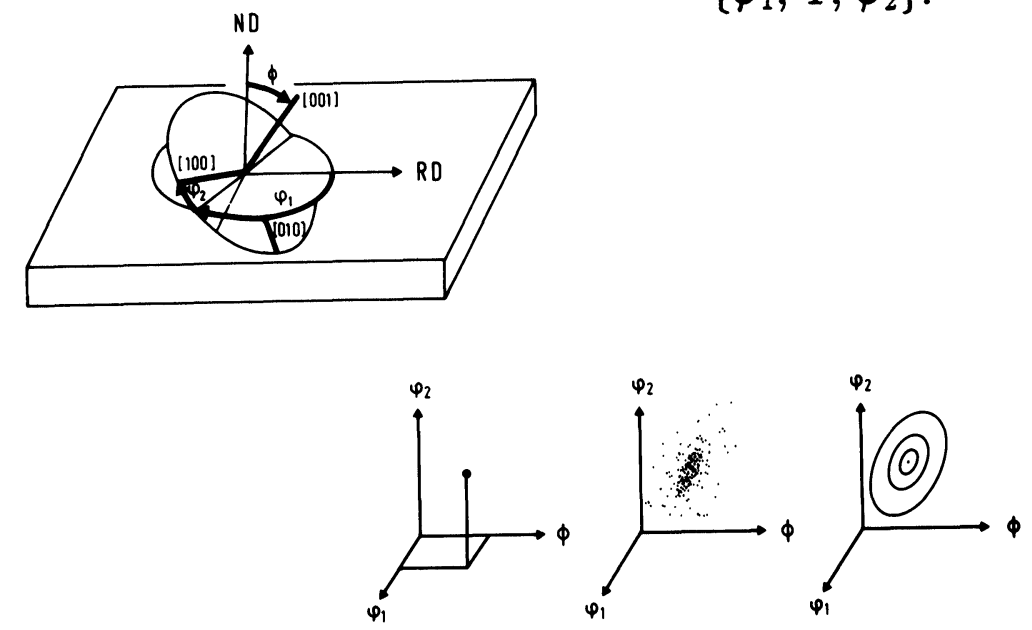

Fig.6 Representation of orientations in the Euler space.

a) Individual orientation point.

b) Orientation points of all crystallites of the sample.

c) Continuous orientation density function.

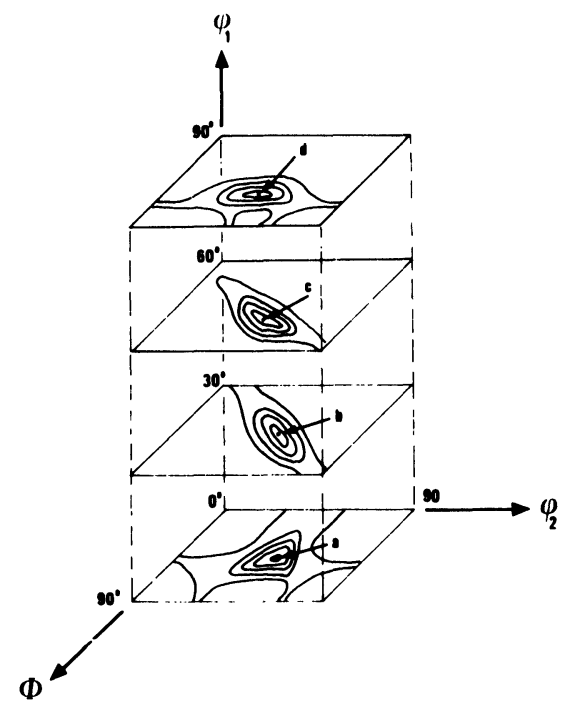

Fig.7 Orientation distribution function, ODF, represented by equilevel surfaces in the three dimensional space or by equilevel lines in two-dimensional sections. 
rolling and normal direction of a sheet have been used to specify so called "ideal orientations" mostly in metals. The Eulerian angles are preferred to describe continuous orientation distributions, and also the coordinate tranformation matrix is a possible description of the orientation $\mathrm{g}$

$$
g=\left[\begin{array}{lll}
g_{11} & g_{12} & g_{13} \\
g_{21} & g_{22} & g_{23} \\
g_{31} & g_{32} & g_{33}
\end{array}\right]=(h k l)[u v w]=\left\{\varphi_{1} \Phi \varphi_{2}\right\}
$$

The three Eulerian angles $\varphi_{1}, \Phi, \varphi_{2}$ can be plotted as cartesian coordinates (in a three-dimensional space). Each orientation is then specified by a point in this orientation space (i.e. the Euler space), Fig.6a. The orientations of all crystals of a material are represented by a "cloud" of orientation points, Fig $6 \mathrm{~b}$, out of which finally a continuous orientation density function (ODF) can be constructed as is shown schematically in Fig.6c. The texture of the material is then characterized by the orientation distribution of the volume fraction of crystals in the orientation $g$

$$
\frac{d V / V}{d g}=f(g)=f\left(\varphi_{1} \Phi \varphi_{2}\right) \quad \mathrm{ODF}
$$

This function can be represented by equi-density lines or surfaces in the Eulerspace as is shown schematically in Fig.7.

Orientation distribution functions can be represented in the form of a series expansion. ${ }^{1,2}$

$$
f\left(\varphi_{1} \Phi \varphi_{2}\right)=\sum_{\lambda=0}^{\infty} \sum_{\mu=1}^{M(\lambda)} \sum_{\nu=1}^{N(\lambda)} C_{\lambda}^{\mu \nu} \cdot T_{\lambda}^{\mu \nu}\left(\varphi_{1} \Phi \varphi_{2}\right)
$$

Where the $T_{\lambda}^{\mu \nu}$ are harmonic functions of the orientation angles $\varphi_{1}, \Phi, \varphi_{2}$. The distribution function is then completely characterized by the infinite series of coefficients $C_{\lambda}^{\mu \nu}$. The coefficients can be expressed by the functions themselves

$$
C_{\lambda}^{\mu \nu}=(2 \lambda+1) \oint f(g) \cdot T_{\lambda}^{\mu \nu}(g) d g=<T_{\lambda}^{\mu \nu}(g)>
$$

They are the orientation mean values of the orientation dependent quantities $T_{\lambda}^{\mu \nu}(g)$. These latter quantities have also been called the 

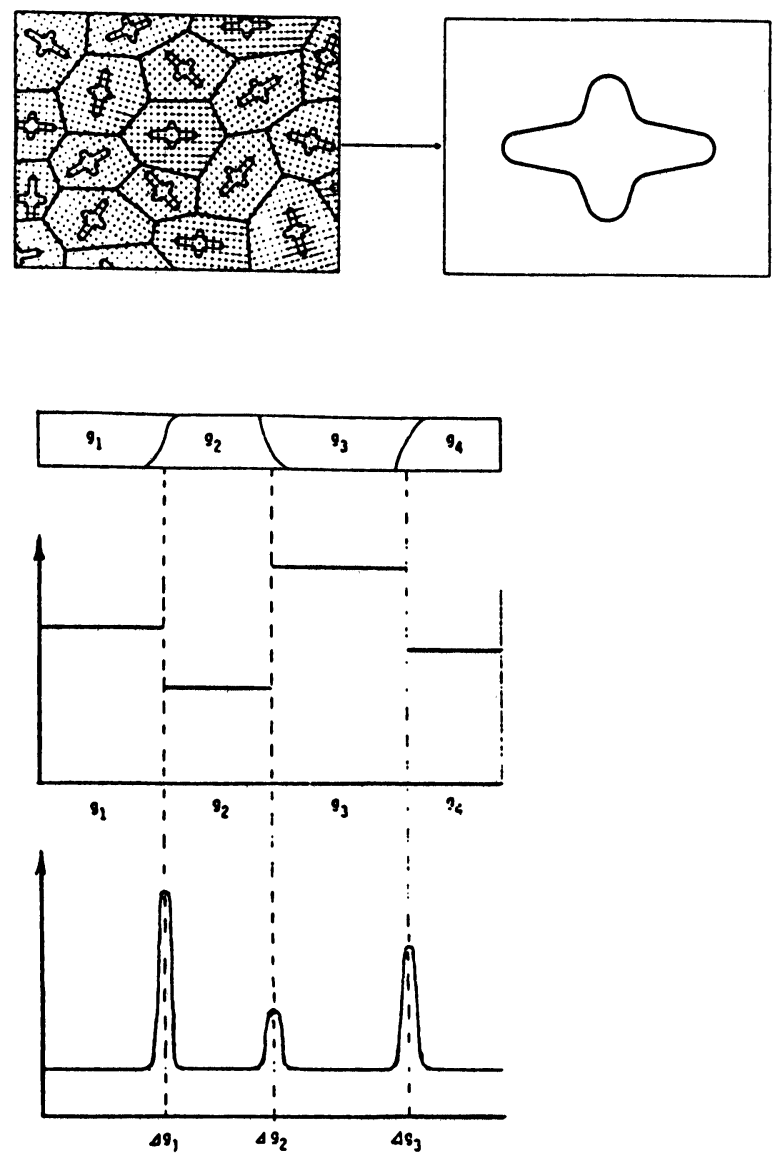

Fig.8 Three kinds of general properties common to all polycrystalline materials.

a) Macroanisotropy.

b) Microheterogeneity.

c) Boundary heterogeneity.

$K_{A} \quad K_{B}^{1}-\Delta g \rightarrow K_{B}^{2}$

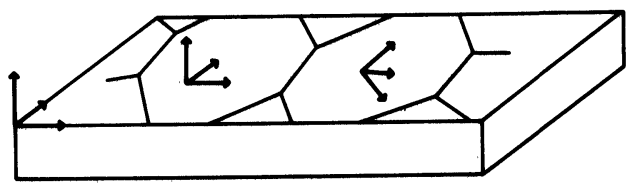

Fig.9 Orientation difference (misorientation) of neighbouring crystals. 
"momenta" of the orientation distribution function $\mathrm{f}(\mathrm{g})$. Approximate representations of the orientation distribution function can then be obtained with only a small number of low-order momenta.

Textured polycrystalline materials generally exhibit three kinds of properties which are closely related to crystal orientation and texture as is shown schematically in Fig.8.

- Since most of the physical properties of crystallites are anisotropic (micro-anisotropy) the material as a whole may also exhibit an anisotropy if the orientation distribution of the anisotropic crystals is not random (macro-anisotropy), Fig.8a. This applies to many physical and technological properties and it is the reason for most of all technologically motivated texture studies.

- The same micro-anisotropy of the crystallites gives rise to discontinuities of the property values accross the grain boundary as is shown schematically in Fig.8b. An example of this effect are internal stresses of second kind which arise as a consequence of different thermal expansion of neighbouring grains.

- Finally, the grain boundaries themselves may have deviating properties compared with the bulk properties of the material. As an example the diffusion coefficient may be mentioned, the value of which may be several orders of magnitude higher than that of the bulk material (Fig.8c).

The crystallographic anisotropy of a physical property can be described by the ratio of highest to lowest value of an appropriately chosen parameter depending on crystal direction (e.g. Young's modulus)

$$
A_{\text {crystal }}=\frac{E_{\max }}{E_{\min }}-1
$$

The macroscopic anisotropy is then given by the product of crystal anisotropy and a texture factor $T .^{3,4}$

$$
A_{\text {macrosc. }}=A_{\text {crystal }} \cdot T
$$

The texture factor depends on the orientation distribution of the crystallites and it is zero for random orientation distribution. The 


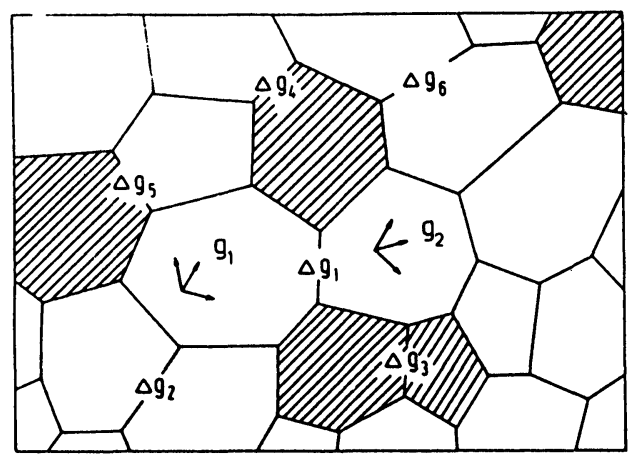

Fig.10 In a polyphase structure each phase has its own ODF and grain boundary MODF. Each pair of phases has it own phase boundary MODF.

\section{CLASSES OF POLYCRYSTALLINE MATERIALS}

A) TECHNOLOGICAL MATERIALS

\section{MEIALSS}

Base metals

Rare metals

Alloys

Intermetallics
Ceramiçs

Silicates

Oxides

Nitrides

Carbides

COMPOSITES

\section{POLYMEERS}

Thermoplastics Duroplastics

Elastomers

B) NATURAL MATERIALS

$\begin{array}{ll}\text { GEOLOGIC } & \text { Biologic } \\ \text { Minerals } & \text { Bones } \\ \text { Ores } & \text { Shells } \\ \text { Rocks } & \text { Bladder stones } \\ \text { Salts } & \text { Teeth } \\ \text { Ice } & \end{array}$

Fig.11 Classification of polycrystalline materials. 
macroscopic anisotropy and its dependence on the materials texture is the main reason for most of all technologically oriented texture studies. ${ }^{5}$ It is also to be mentioned that the texture factor can be expressed by only a few low-order texture coefficients $C_{\lambda}^{\mu \nu}$ (or momenta) defined in eq.5.

The other two properties shown in Fig.8, i.e. microheterogeneity and boundary heterogeneity depend primarily on the orientation difference $\Delta g$ of neighbouring crystals which is illustrated in Fig.9. The two crystal coordinate systems of the two neighbour crystals are related to each other by the orientation difference (or misorientation) $\Delta g$

$$
K_{B}^{2}=\Delta g \cdot K_{B}^{1}
$$

A misorientation $\Delta g$ can be specified by Eulerian angles, too, similar to eq.2. Then the misorientation density function $\mathrm{F}(\Delta g)$, the MODF, can be specified in a very similar manner to the ODF. ${ }^{6}$

$$
\frac{d A / A}{d \Delta g}=F(\Delta g)=F\left(\varphi_{1} \Phi \varphi_{2}\right) \quad \text { MODF }
$$

Thereby $d A / A$ is the area fraction of boundaries having the misorientation $\Delta g$.

If the crystalline material consists of several phases, Fig.10, then an ODF has to be defined for each phase and MODFs have to be defined for each kind of boundaries, i.e. grain and phase boundaries of each phase or each pair of phases. ${ }^{7}$

The ODF is mainly obtained from pole figures by the mathematical process of pole figure inversion. The pole figures can be measured by X-ray, neutron or electron diffraction. The MODF can only be obtained from individual grain orientation measurements which are mainly carried out by electron diffraction.

The definitions of the ODF, eq.3, and the MODF, eq.5, apply to any kind of crystalline materials a classification of which is given in Fig.11. The application of these methods in the various classes of materials has been, however, quite different. ${ }^{3}$

Metals

- Texture studies in metals have been carried out virtually immediately after the invention of X-ray diffraction. ${ }^{8}$ 
- A comprehensive survey of the occurence of textures in all basic metals and their influence on the materials properties has been given by Wassermann and Grewen ${ }^{9}$ in 1962 . In this work, the texture is mainly represeneted by pole figures which were interpreted in terms of ideal orientations.

- ODF-analysis in metals was used for the first time in $1965 .{ }^{10,11} \mathrm{~A}$ comprehensive description was given by Bunge $^{1}$ 1982. Today, ODF-analysis in base-metals can be regarded as a routine procedure.

- Texture analysis in metals is also used, today, as an on-line process in continuous metal production lines. ${ }^{12}$

- ODF-analysis in intermetallic materials is just at the beginning. ${ }^{13}$

\section{$\underline{\text { Ceramics }}$}

- Texture studies (in the above mentioned sense) in ceramic materials have been first applied to hard magnetic ferrites having uniaxial anisotropy (macroscopic as well as microscopic). Quantitative pole figures could be related quantitatively to the anisotropy of remanence and other physical properties. ${ }^{14,15}$

- Complete ODF analysis in ceramics has only been used recently. ${ }^{16}$

\section{$\underline{\text { Polymers }}$}

- Textural anisotropy in polymers has been considered since a long time. ${ }^{17,18,19}$

- Complete ODF analysis was also introduced rather early. ${ }^{20,11}$ Contrary to the situation in metals, it has found, however, only much less practical application thus far. ${ }^{21,22}$ This situation is about to change only in the last few years. ${ }^{23}$

$\underline{\text { Geological materials }}$

- In geological materials textures have been considered for a long time mainly in two ways: 

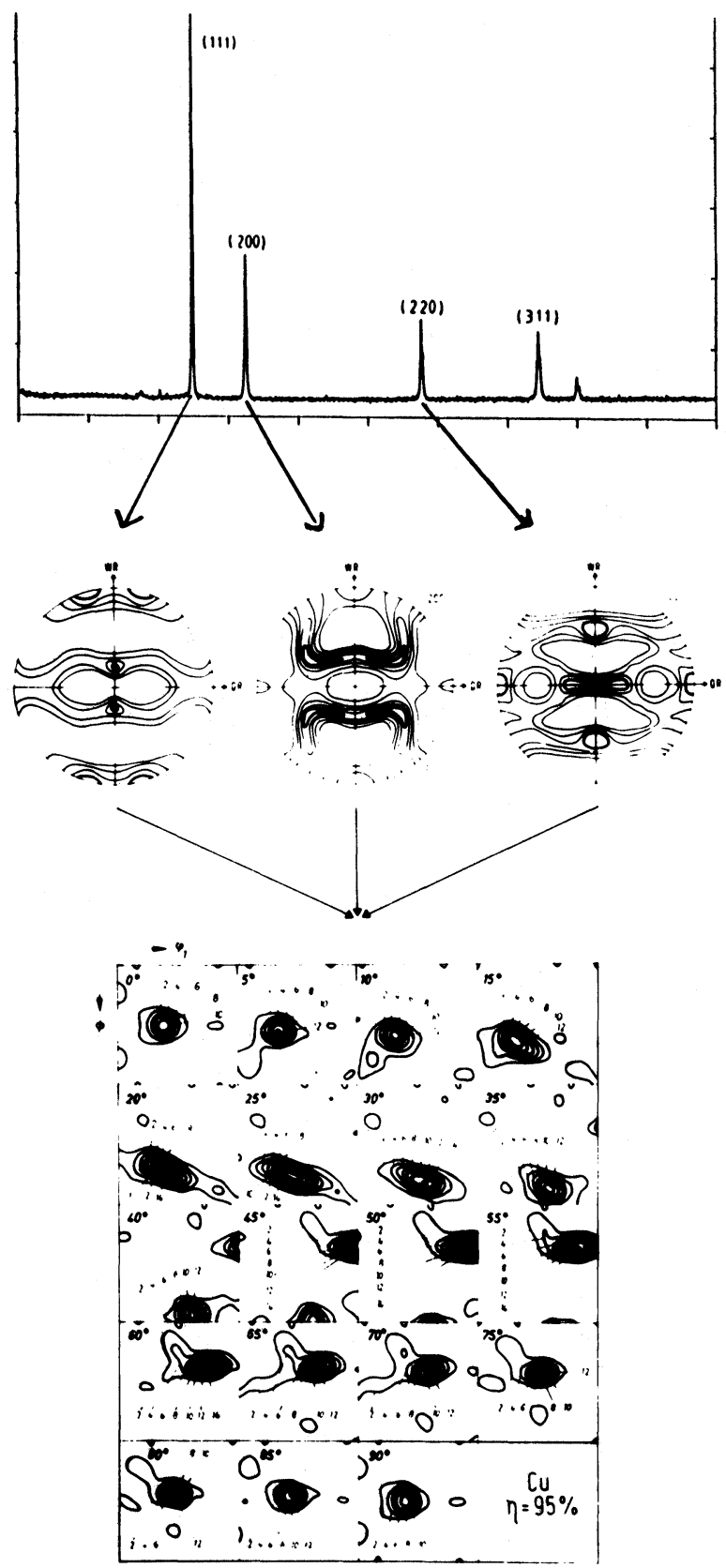

Fig.12 Texture determination (cold rolled copper).

a) Intensity disribution in the $2 \boldsymbol{v}$-diagram.

b) Pole figure of the most important diffraction peaks.

c) ODF calculated from pole figures. 
- Crystal orientation of optically transparent materials can be obtained from birefringence, using polarised light. This method was mainly used for texture investigations of optically uniaxial materials such as quartzite. ${ }^{24}$

It allows only the c-axis distribution to be determined and it is rather time consuming.

- Also X-ray diffraction has been used to determine pole figures.

- Complete ODF-analysis was introduced much later. ${ }^{25}$ It is, however, coming more and more into use, now. ${ }^{26}$

\section{DIFFERENCES IN TEXTURE ANA- LYSIS BETWEEN METALS AND NON-METALS}

Texture analysis is mostly carried out by polycrystal diffraction using $\mathrm{X}$-rays, neutrons or electrons. By scanning the Bragg-angle $\vartheta$, a polycristal diffraction diagram is obtained. The intensity of any diffraction peak depends on the volume fraction of crystals which are in diffraction position in the considered sample direction. Hence, the intensity ratios of the diffraction peaks are a first (qualitative) indication of the texture of the material.

The next step may be to rotate the sample through all possible angular positions $(\alpha, \beta)$ and to measure the intensities as a function of $(\alpha, \beta)$. One thus obtains the pole "figures" corresponding to the diffraction peaks (hkl).

Finally, from several such pole figures the ODF can be calculated using a mathematical procedure called "pole figure inversion" This is shown schematically in Fig.12.

Hence, the definition of the texture, i.e. the ODF, according to eq.3 and the method of how to measure it is essentially the same for all crystalline materials. Thus, the question arises why texture studies have been done so extensively in metals but only very little (at least with the quantitative ODF-methods) in non-metallic materials. This has different reasons which will be considered in the following. 


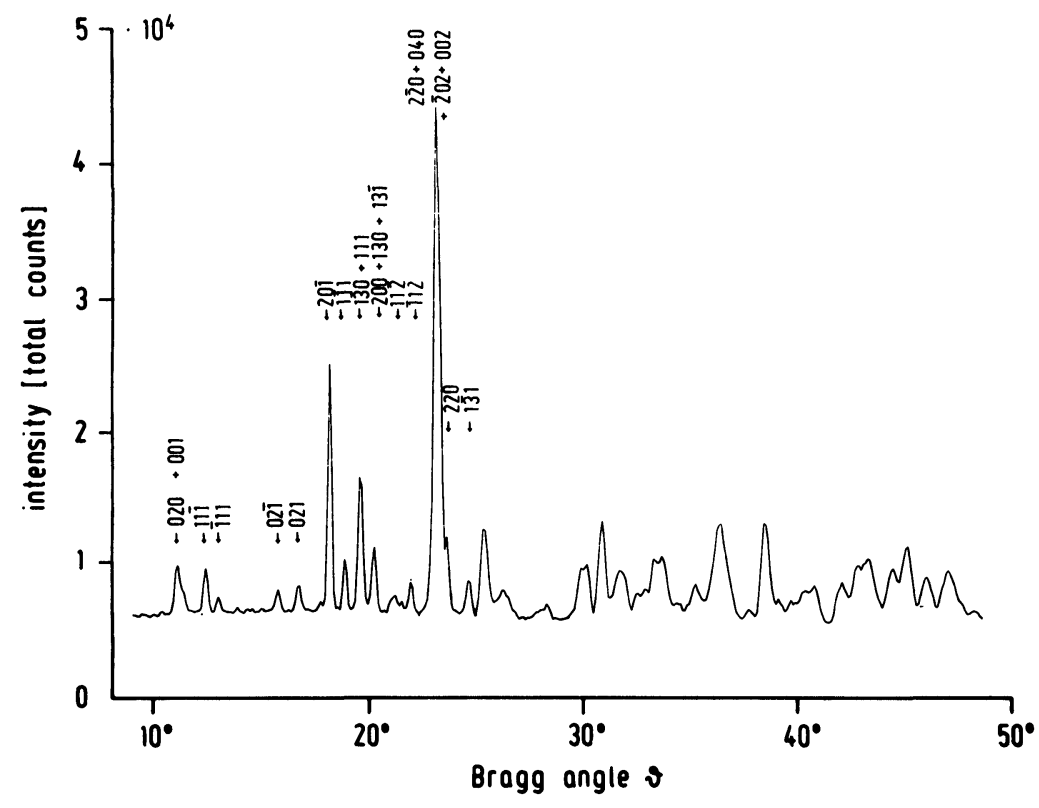

Fig.13 Diffraction diagram showing a large number of partially and totally overlapped peaks.

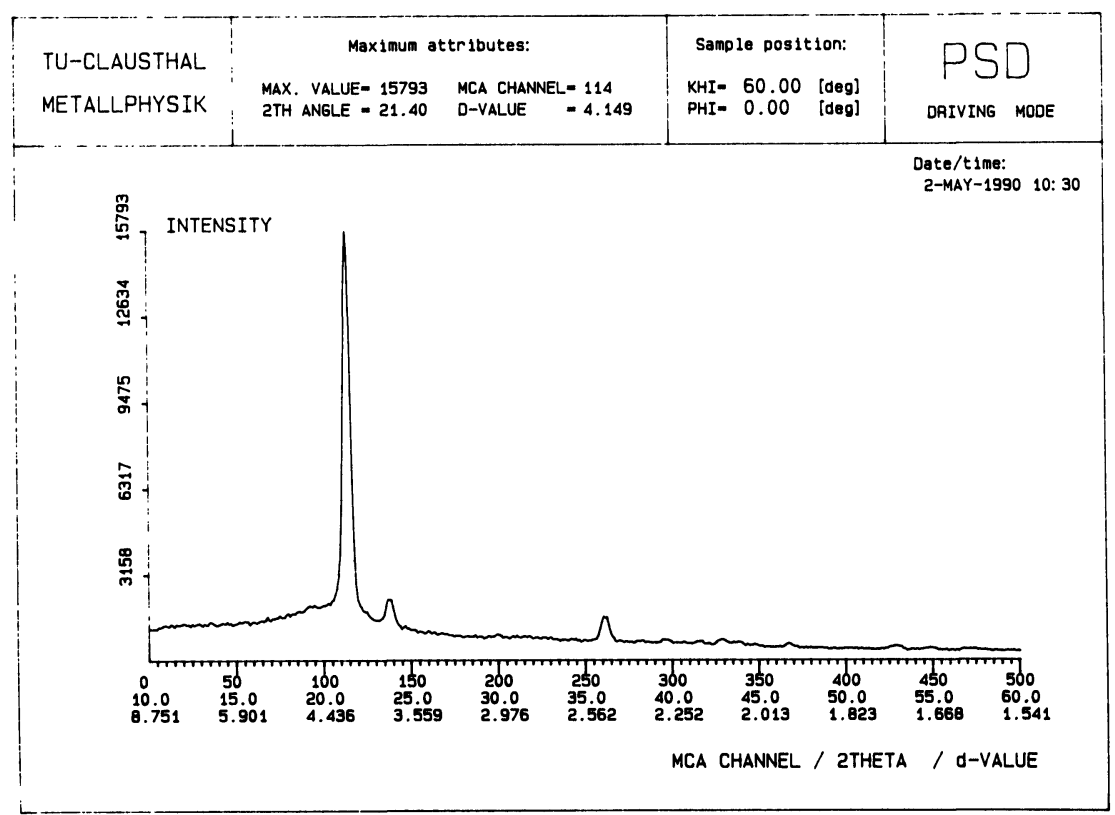

Fig.14 Diffraction diagram of polyethylene with only a very low number of suffiently strong diffraction peaks. 


\subsection{Experimental complications}

Tab. 1 summarizes some of the differences between metals, ceramics and polymers. Whereas metals are, in most cases, completely crystalline, the other two types of materials may contain considerable amounts of non-crystalline "phases". Some types of ceramics are not "dense", they may contain up to say $20 \%$ of pores. Hence, the properties of such materials may be dominanted by the amount, size, shape and arrangement of pores, rendering the influence of texture of the crystalline part much smaller. Besides this, also a non-crystalline glass phase may be present. In polymers, the "crystallinity" may range from zero to $100 \%$. The definition of texture as given above applies, of course, only to the crystalline part.

A second distinction is crystal symmetry. Whereas the base metals have highest symmetries i.e. cubic or close-packed hexagonal, the symmetries of ceramic materials range from cubic to triclinic and those of polymers are mostly orthorhombic to triclinic. This requires the developement of new computer programs and the execution of these programs requires more storage space and longer calculation times. Along with lower crystal symmetries, the non-metallic materials have often much higher lattice parameters. Low symmetry and high lattice parameters result in a large number of diffraction peaks. This, in turn, leads to peak overlapping, especially at higher tilt angles $\alpha$ in pole figure measurement. An example of such a diffraction diagram is shown in Fig.13. Hence, texture analysis in these materials requires peak separation techniques. The first step in this direction is the use of a position sensitive detector combined with peak profile analysis programs which allow to determine the correct integrated intensity of broadened and overlapped peaks. ${ }^{27}$ This procedure of peak separation must, however, fail if the peak positions are too close to each other or if they are identical at all. But even this case can be handled by modifying the pole figure inversion programs in such a way that superposed pole figures can be used as input data. ${ }^{1,28,29}$

But also the opposite case may be encountered. Fig.14 shows a diffraction diagram of a polymer material which has only a low number of sufficiently strong diffraction peaks. In this case the mathematical procedure of pole figure inversion may suffer from shortage of experimental input data: the computer codes for pole figure inver- 


\begin{tabular}{|c|c|c|c|c|c|}
\hline Material & $\begin{array}{c}\text { Non- } \\
\text { crystalline } \\
\text { fraction }\end{array}$ & $\begin{array}{c}\text { Crystal } \\
\text { symmetry }\end{array}$ & $\begin{array}{c}\text { Lattice } \\
\text { parameter }\end{array}$ & $\begin{array}{c}\text { Lattice } \\
\text { perfection } \\
\text { (Line } \\
\text { width) }\end{array}$ & $\begin{array}{l}\text { Diffracted } \\
\text { intensity }\end{array}$ \\
\hline Metals & - & $\begin{array}{c}\frac{\text { high }}{\text { cubic }} \\
\text { hexagonal }\end{array}$ & $\begin{array}{l}\underline{\text { low }} \\
\approx 4 \AA\end{array}$ & $\begin{array}{c}\text { high } \\
\text { (narrow) }\end{array}$ & strong \\
\hline Ceramics & $\begin{array}{l}\text { Pores } \\
\text { glassy } \\
\text { phase }\end{array}$ & $\begin{array}{c}\frac{\text { high-low }}{\text { cubic }} \\
: \\
\text { triclinic }\end{array}$ & $\begin{array}{c}\underline{\text { high }} \\
5 . .20 \AA\end{array}$ & $\begin{array}{c}\text { high } \\
\text { (narrow) }\end{array}$ & medium \\
\hline Polymers & $\begin{array}{l}\text { non- } \\
\text { crystalline } \\
\text { phase }\end{array}$ & $\begin{array}{l}\text { low } \\
\text { orthohombic } \\
\text { monoclinic } \\
\text { triclinic }\end{array}$ & $\begin{array}{c}\underline{\text { high }} \\
5 . .20 \AA\end{array}$ & $\begin{array}{c}\text { low } \\
\text { (broad) }\end{array}$ & low \\
\hline
\end{tabular}

Tab.1 Particular features of materials related to texture analysis

sion must then be modified in such a way as to include all additional information about the ODF that can be made available. A first step in this direction is to make consequently use of the positivity of the $\mathrm{ODF}$ and the pole figures. ${ }^{28,29}$

Further experimental complications may be low diffraction intensities which require long measuring times and lead to low peak-tobackground ratios.

And finally in some materials the texture is "camouflaged". This means that the strongest diffraction peaks (see Fig.12) may correspond to rather flat pole figures although the texture itself is by no means flat. (An example of such a camouflaged texture will be shown lateron).

Hence, it can be concluded that the experimental complications, which stand in the way of texture analysis in non-metallic materials can be overcame today by using first of all position sensitive detectors and more sophisticated computer codes for the calculation of ODF from diffraction data. 

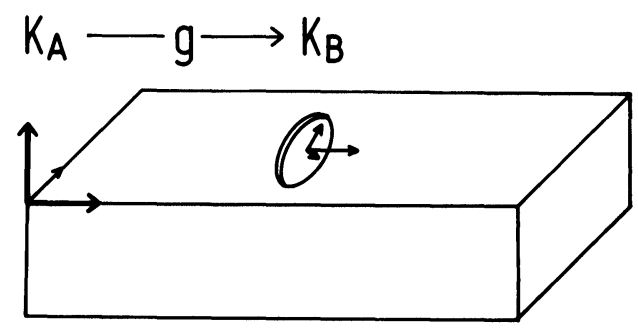

Fig.15 Definition of the "shape"orientation of a grain in a polycrystal sample.
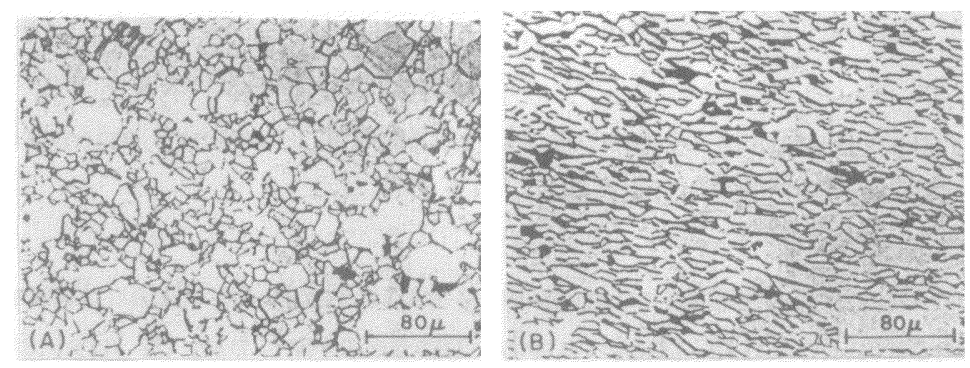

Fig.16 Shape texture of a sinter forged sample of $\mathrm{Al}_{2} \mathrm{O}_{3}{ }^{30,31}$

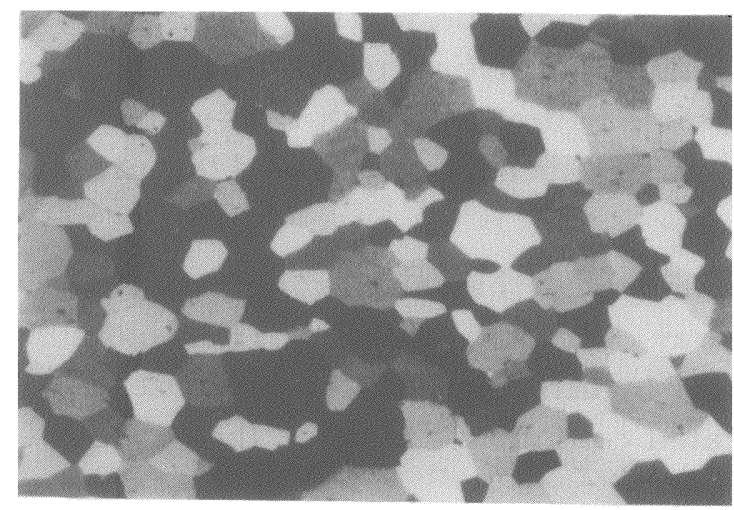

Fig.17 Grain structure of AlMn1 with strong cube texture (but no shape texture). 


\subsection{Alternative definition of the term "texture"}

Besides the experimental complications in texture determination in non-metals, there are, however, two further complications which concern the very definition of what we call "texture". These are the "shape texture" often considered in ceramics and the "chain texture" often considered in polymers.

\subsubsection{The shape texture}

If the crystallites of which the material consists have a particular non-spherical shape (e.g. a three axial ellipsoid) then the crystal coordinate system can be fixed to the shape of the crystal (observed in the microscope) rather than to the crystal lattice (observed by $\mathrm{X}$-ray diffraction). This is shown schematically in Fig.15. Formally, the definition of the orientation $\mathrm{g}$ remains the same as that given in eq. 1 and also the definition of the ODF remains the same as in eq.3. Only the definition of the crystal coordinate system $K_{B}$ is different.

The shape of crystals is often plate-like or needle-like. Then only one axis of the shape coordinate system can be fixed i.e. the needle axis or the plate normal direction. A rotation of the particles about this direction cannot be distinguished. In this case, the shape texture "sees" only two of the three Eulerian angles namely $\varphi_{1}$ and $\Phi$. The angle $\varphi_{2}$ which describes a rotation about the crystal $\mathrm{Z}$-axis remains unresolved. The shape ODF is then only two-dimensional

$$
\frac{d V / V}{d \Omega}=f\left(\varphi_{1} \Phi\right)
$$

This means, it is only a "shape pole figure".

If the shape of the particles is crystallographically determined, then the shape coordinate system may be strictly related to the crystal lattice by which the crystal coordinate system eq.1 was defined. In this case both definitions, the shape texture and the lattice texture, are essentially the same. The normal directions of plate-like particles as well as the axis direction of needles are often parallel to the crystallographic c-axis whereas the axes $a$ and $b$ can often not be discerned. In this case the c-axis distribution can be obtained by shape texture methods. In ceramics, one often encounters the 


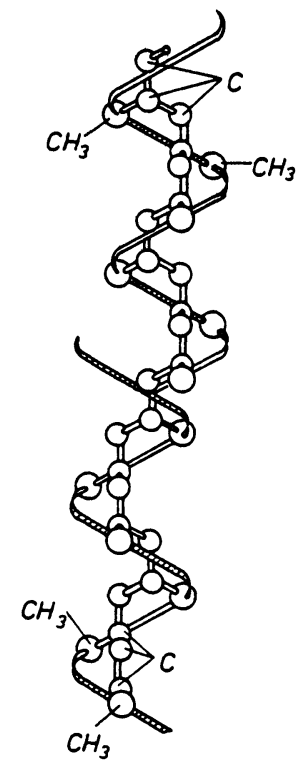

Fig.18 A polymer chain. ${ }^{18}$

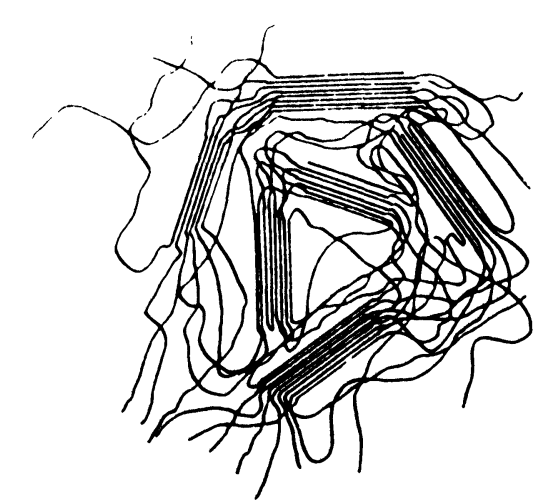

Fig.19 Polymer chains in the crystalline and non-crystalline part ${ }^{32}$

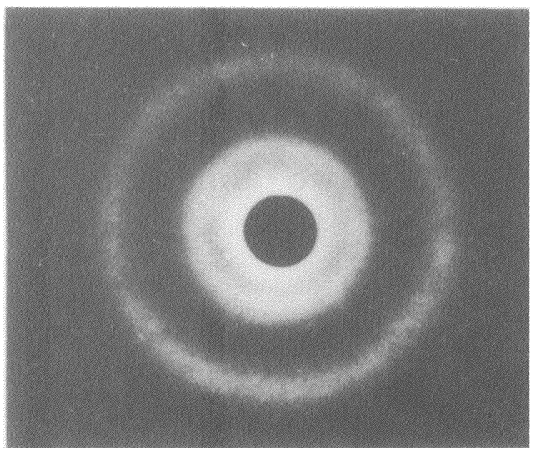

(a)

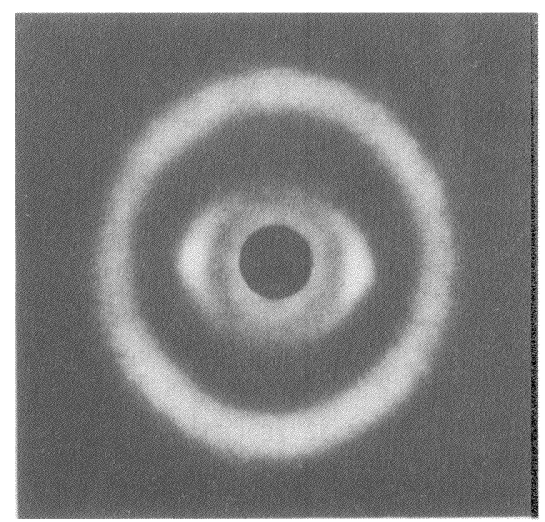

(b)

Fig.20 Distribution of X-ray diffraction intensities in two non-crystalline polymers stretched in vertical direction ${ }^{33}$ 
situation that the shape texture is related to the "lattice" texture whereas in metals this is mostly not the case

$$
\begin{array}{rll}
\text { shape texture } & \text { lattice texture } & \text { (ceramics) } \\
& \text { lattice texture } & \text { (metals) }
\end{array}
$$

Fig. 16 shows a sinter-forged $\mathrm{Al}_{2} \mathrm{O}_{3}$ sample which has a pronounced shape texture ${ }^{30}$ and at the same time a lattice texture with the basal plane perpendicular to the press direction. ${ }^{31}$ On the other hand, Fig. 17 is a recrystallized AlMn sample with strong cube texture but with no shape texture.

\subsubsection{The chain texture}

Polymer materials consist of long chains Fig.18. ${ }^{32}$ For many questions, the orientation of the chain axis is much more important than the angular position of a rotation about the chain axis. Then the orientation distribution of the axes may be considered as the chain texture. ${ }^{33}$

$$
\frac{d V / V}{d \Omega}=P\left(\varphi_{1} \Phi\right) \quad \text { chain texture (general) }
$$

Thereby $d V / V$ is the volume fraction of chains, the axes of which have the direction described by $\varphi_{1}$ and $\Phi$ with respect to a sample coordinate system.

The chains may be strictly ordered in the crystalline part of the material or they may be "tangled" in the non-crystalline part. The above definition of the chain texture applies to both parts, Fig.19.32 Also in the non-crystalline tangles certain directions may be preferred to others.

If we know the ODF of the crystalline part, then the chain texture of this part can be deduced immediately. Let as assume that we have chosen the crystal coordinate system in such a way that the crystal c-axis is the chain direction then the chain texture is simply the integral of the ODF over $\varphi_{2}$.

$$
P\left(\varphi_{1} \Phi\right)=\frac{1}{2 \pi} \int f\left(\varphi_{1} \Phi \varphi_{2}\right) d \varphi_{2}
$$

Most generally speaking, if the chain axis is the crystallographic direction $h$ then the chain texture is given by the $h$-pole figure which 

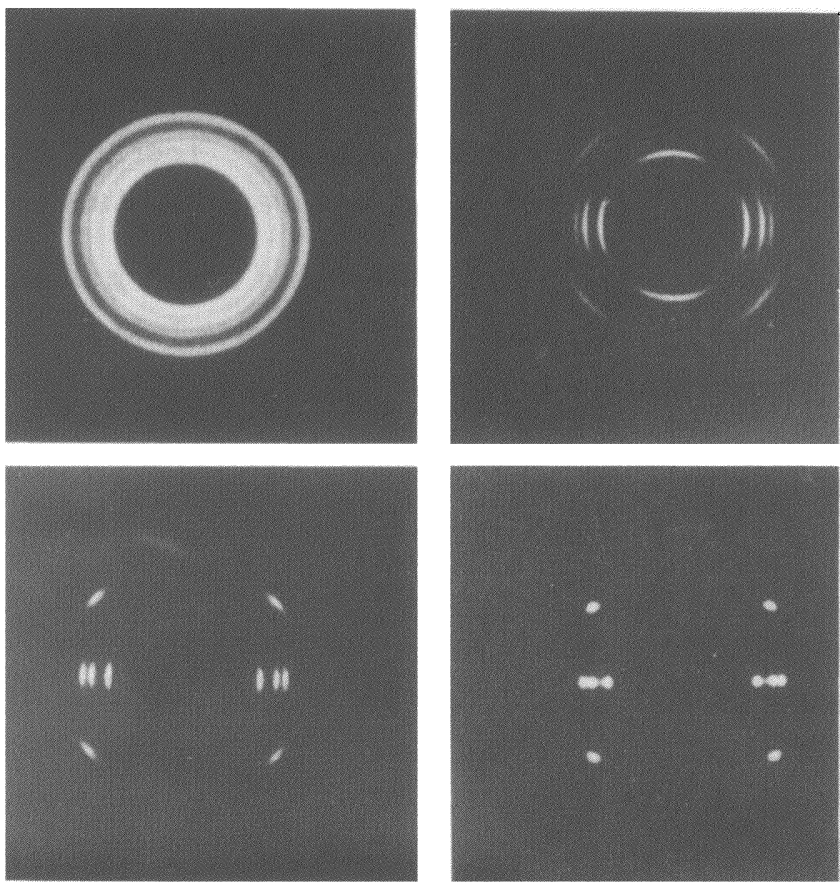

Fig.21 X-ray diffraction diagrams of crystalline polypropylene after different degrees of stretching in perpendicular direction. ${ }^{33}$
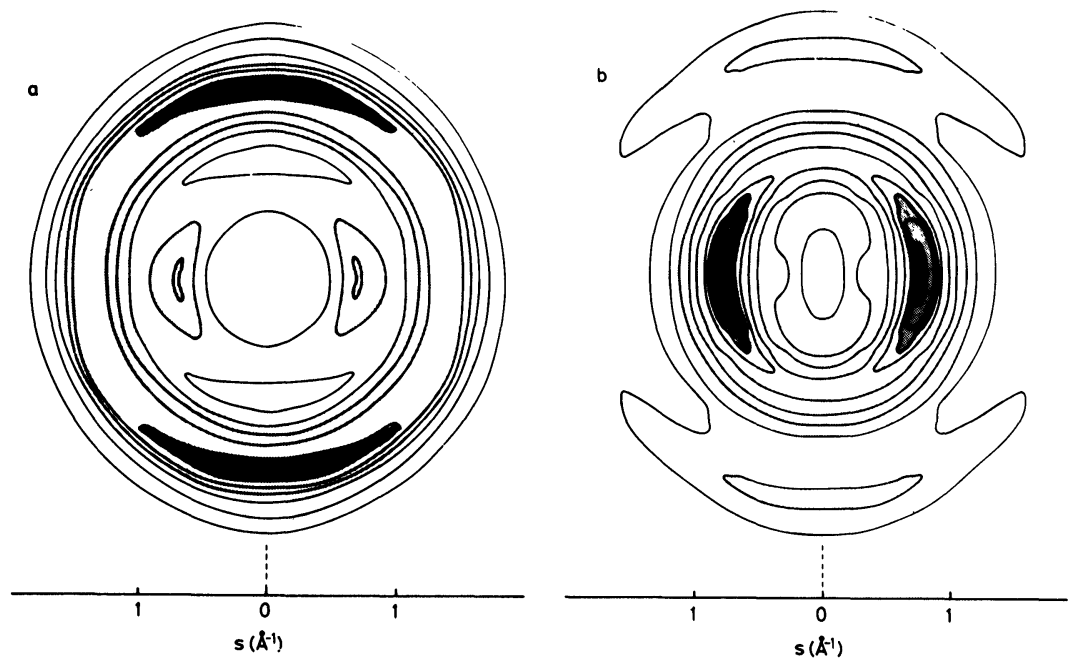

Fig.22 X-ray diffraction diagram of non-crystalline polystyrene befor and after stretching. ${ }^{33}$ 
can be deduced from the ODF. If the material is non-crystalline then the chain texture can be calculated from diffuse X-ray diffraction diagrams in the wide angle range (WAXD). ${ }^{34}$ Fig. 20 shows, for instance, the intensity distribution of two uniaxially stretched polymer samples. From diagrams like that, it is, in principle,possible to calculate the complete chain texture according to eq.133. If the sample was uniaxially stretched (as in Fig. 20), then the diffraction diagram and hence the chain texture is independent of the angle $\varphi_{1}$ which measures a rotation about the stretching axis. In this case eq.13 simplifies to

$$
\frac{d V / V}{d \Phi}=P(\Phi) \quad \text { chain texture (uniaxial) }
$$

Some physical properties of polymers depend mainly on the chain texture, independent of whether the chains form crystals or not. In this case a similar mean value expression as eq. 7 holds if only one replaces the term "crystal" by "chain segment" and the ODF $\mathrm{f}(\mathrm{g})$ by the chain texture $\mathrm{P}\left(\varphi_{1} \Phi\right)$. If one knows the anisotropy of an individual chain segment and measures the macroscopic anisotropy then one obtains information obout the texture (in this case the chain texture). This procedure does, however, not give the complete chain textures, it rather allows to determine the low-order "momenta" of this function similar to those defined in eq. 5 for the ODF. Physical properties, which have been used, in this sense, for texture analysis are, among others, NMR, infrared dichroism or fluorescence polarisation. ${ }^{35,36}$

Hence, the methods of texture analysis in polymers can be summarized as shown in Tab.2.

\section{TEXTURES IN POLYMERS}

Polymers can develop very high degrees of preferred orientation. ${ }^{37,38}$ Fig.21 shows, for instance, $\mathrm{X}$-ray diffraction photographs of crystalline polypropylene ${ }^{33}$ after different degrees of drawing. In the initial state the texture was virtually random, whereas the last picture shows a rather sharp point diagram which is due to a very sharp fibre texture. The same is also observed in non-crystalline materi- 


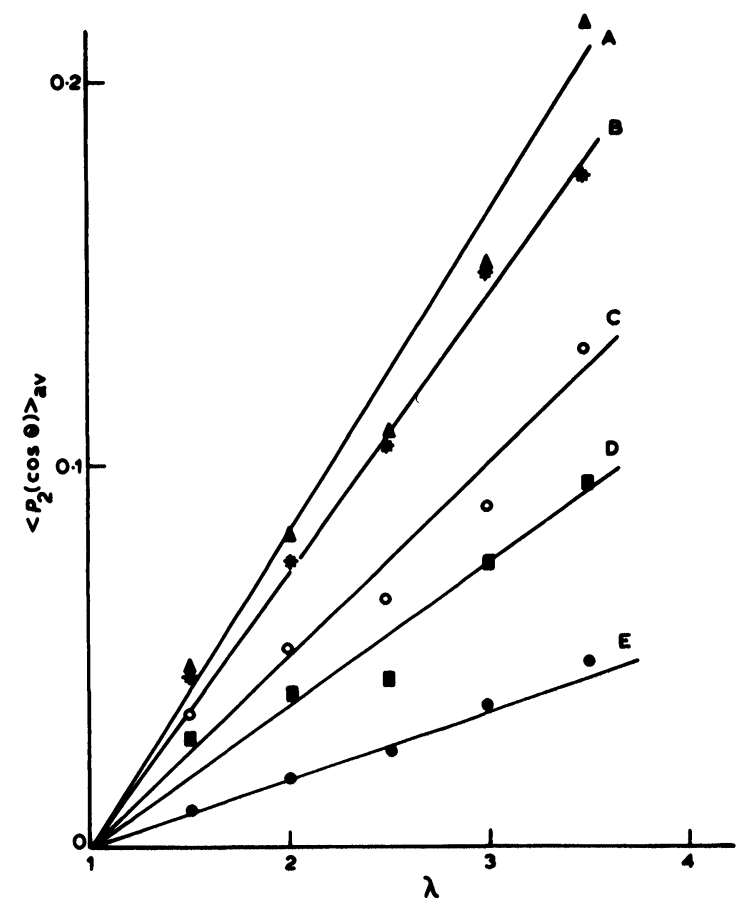

Fig.23 The second momentum of the orientation distribution function of polystyrene after stretching with different strain rates as a function of the draw ratio. ${ }^{36}$
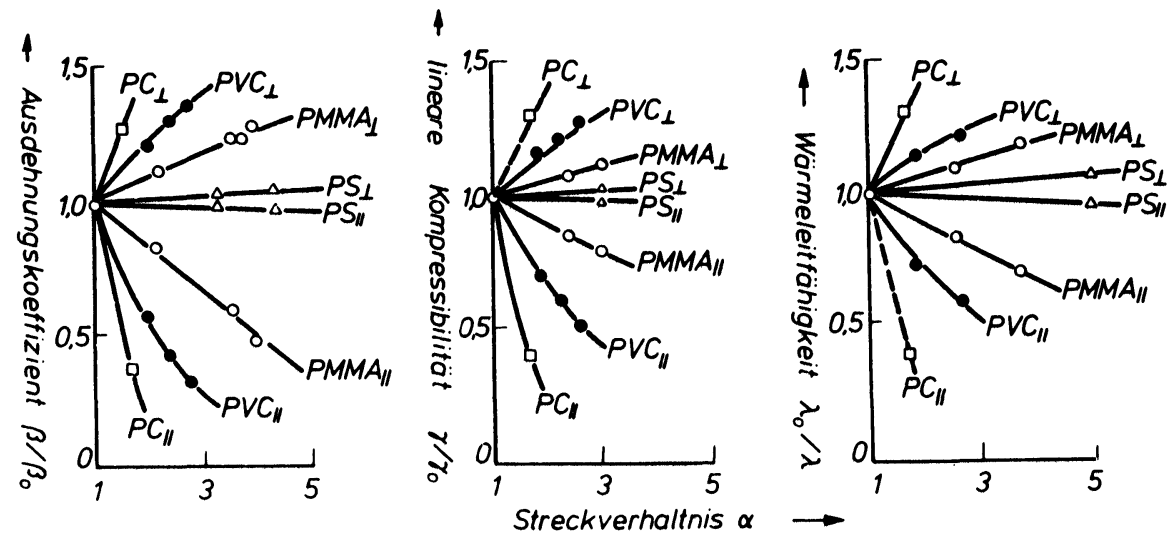

Fig.24 Variation of some physical properties parallel and perpendicular to the stretching direction of several polymers as a function of the draw ratio. ${ }^{32}$

$\mathrm{PC}=$ polycarbonate

$\mathrm{PVC}=$ polyvinylchloride

PMMA = polyacrylate

$\mathrm{PS}=$ polystyrole 

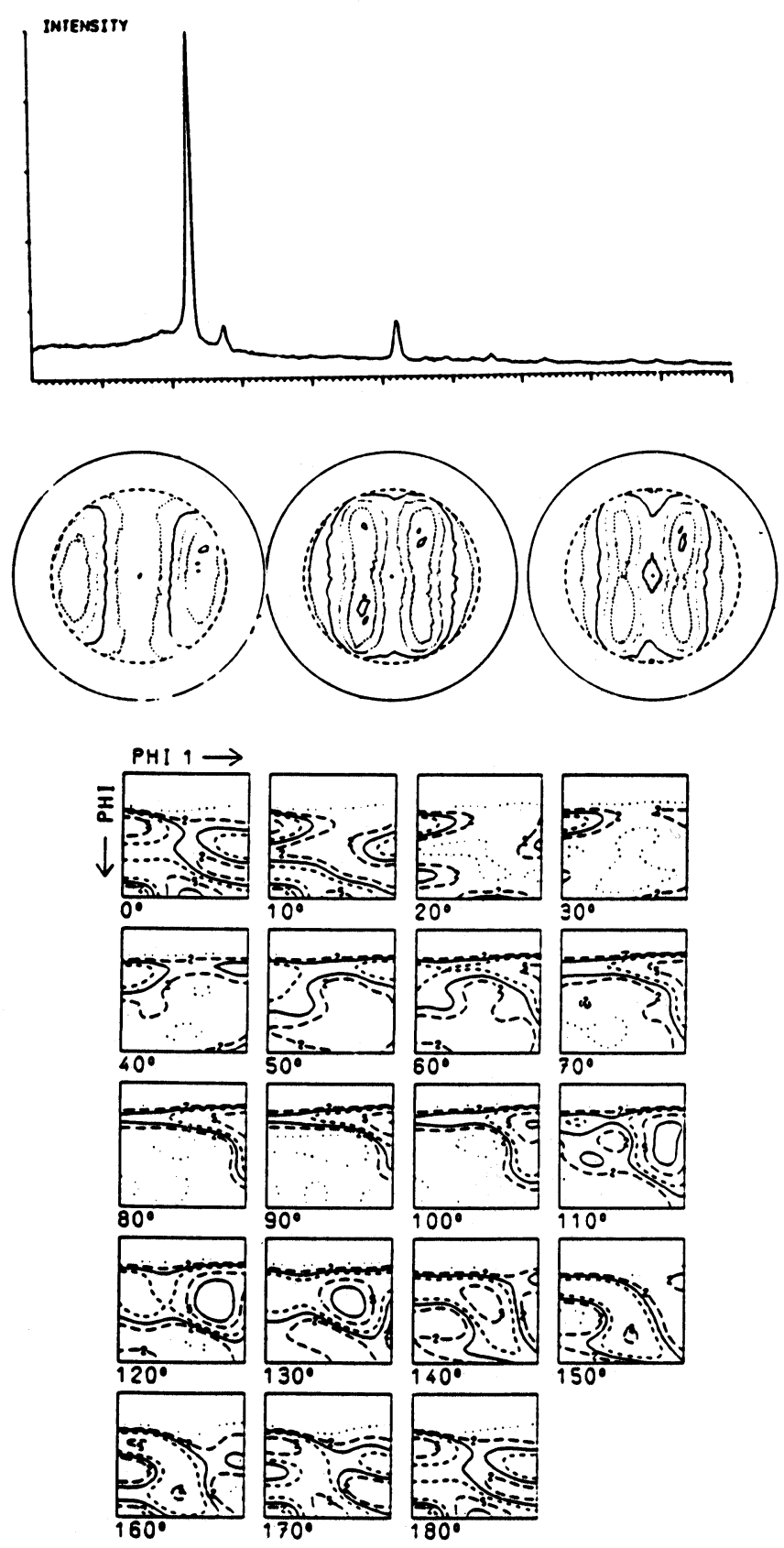

Fig.25 ODF analysis in biaxially drawn polyethylene.
a) 2v-diagram.
b) Pole figures.
c) ODF. 


\begin{tabular}{|c||c|c|c|}
\hline Method & $\begin{array}{c}\text { structural } \\
\text { part }\end{array}$ & ODF & chain texture \\
\hline \hline WAXD & $\begin{array}{c}\text { crystalline } \\
-\ldots-\ldots-- \\
\text { non-crystalline }\end{array}$ & complete & complete \\
\hline $\begin{array}{c}\text { physical } \\
\text { properties }\end{array}$ & $\begin{array}{c}\text { crystalline } \\
+\end{array}$ & & $\begin{array}{c}\text { complete } \\
\text { non-crystalline }\end{array}$ \\
\hline
\end{tabular}

Tab.2 Methods of preferred orientation analysis in polymers

als. Fig.22 shows $\mathrm{X}$-ray diffraction photographs of non-crystalline polystyrene before and after drawing. ${ }^{33}$

The texture formation can be followed quantitavely as a function of the drawing ratio as is shown in Fig.23 for polystyrene samples drawn with different strain rates. ${ }^{36}$ The texture parameter $\left\langle P_{2}(\cos \Theta)\right\rangle_{a v}$ is the second momentum of the chain texture (eq.14) determined by the anisotropy of infrared dichroism.

The second order momentum $<P_{2}(\cos \Theta)>_{a v}$ does not describe the chain texture completely. Nevertheless, it is an important parameter since the macro anisotropy of many physical properties depends only on low-order momenta rather than on the complete distribution function. This is a quite general fact which holds for the properties of crystalline materials as well (If eq.7 is expressed in term of coefficients $C_{\lambda}^{\mu \nu}$ then only very few of them enter the expression. ${ }^{1}$ The higher order terms are, so to speak, "averaged out"). Hence, many physical properties of many polymers show a similar dependance on the drawing ratio as the momentum shown in Fig.23. This is shown for instance in Fig.24. ${ }^{32}$

If the process of texture formation itself is to be studied, then the information contained in the low order momenta is, of course, not sufficient. It is then necessary to measure pole figures and to calculate the ODF as is shown for instance in Fig.25 for the crystalline part of a biaxially drawn polyethylene sample ${ }^{39}$ 

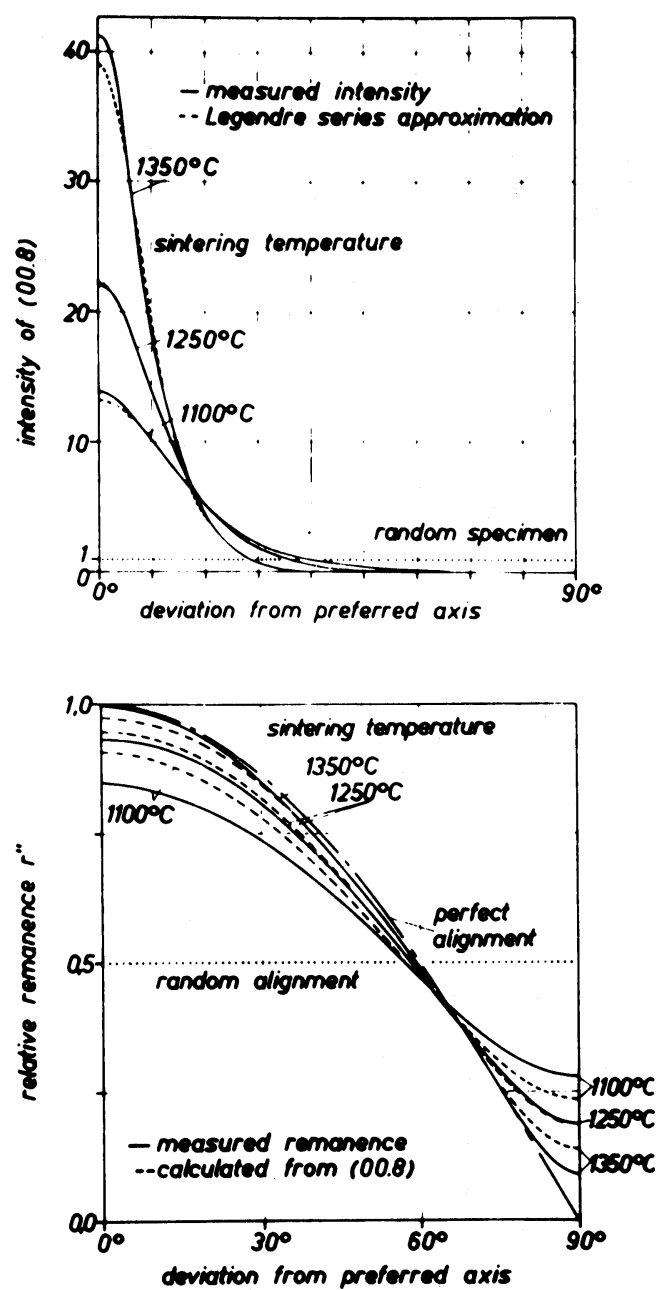

Fig.26 Texture and magnetic anisotropy in Ba-ferrite 14,15

a) pole density of the (0008) reflection after sintering at differnt temperatures.

b) Relative remanence as a function of the angle to the preferred axis.

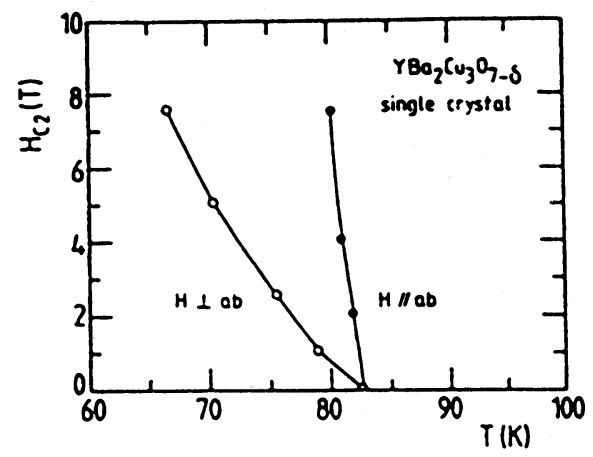

Fig.27 Upper critical field of $\mathrm{YBa}_{2} \mathrm{Cu}_{3} \mathrm{O}_{7-x}$ as a function of temperature, parallel and perpendicular to the a-b plan ${ }^{40}$ 


\begin{tabular}{|l|l|}
\hline Material & Application \\
\hline \hline Porcelaine & Table ware \\
Steatite & Isolators \\
Titanates $\mathrm{BaTiO}_{3}$ & Ferroelectrics \\
\multicolumn{1}{|c|}{$\mathrm{Al}_{2} \mathrm{TiO}_{5}$. } & Automobile motor parts \\
Zirconium oxide & Construction materials \\
Ferrites & Magnetic materials \\
Aluminium oxide & Substrates \\
Berylium oxide & Substrates \\
Boron carbide & Cutting tools \\
Tungsten carbide & Cutting tools \\
Alone & Optical applications \\
Silicon nitride & Construction materials \\
Boron nitride & HT-lubrication \\
Aluminium nitride & Substrates, Isolators \\
\hline
\end{tabular}

Tab.3 Some classes of ceramic materials

\section{TEXTURES IN CERAMICS}

Several classes of ceramic materials are summarized in Tab.3. They are used for different purposes, whereby different physical properties are essential such as mechanical properties in the structural materials, magnetic properties, superconductivity, ferroelectricity, thermal conductivity, expansion and others. In many cases these properties have extreme crystal anisotropies compared with the anisotropies known in highly symmetric metals. Hence, textures play an important role in these materials.

Ceramic magnets were the first ceramic materials in which the production of textures and their influence on materials properties was studied quantitatively more then twenty years ago Fig.26 shows, for instance the basis pole figure (0008) of $\mathrm{Ba}$-Ferrite samples sintered at different temperatures. ${ }^{14,15}$

It is seen that the texture increases with increasing sintering temperatures. The textures were represented in form of a series expansion similar to eq.4. Using eq. 6 the remanence can then be calculated as 

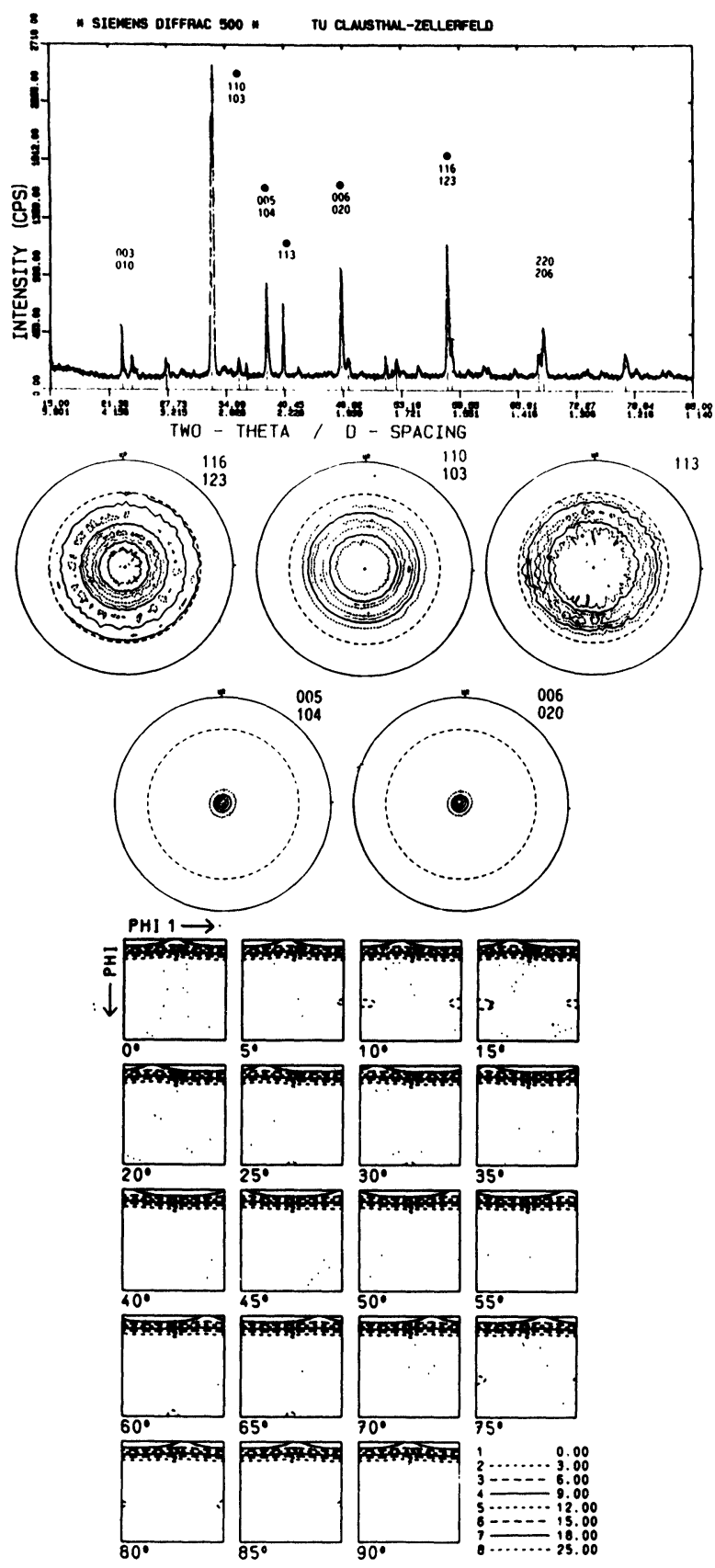

Fig.28 ODF-analysis in $\mathrm{YBa}_{2} \mathrm{Cu}_{3} \mathrm{O}_{7-x}$ powder oriented in a magnetic field.

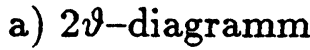
b) Pole figures
c) $\mathrm{ODF}$ 
is also shown in Fig. 26.

$H T_{c}$-superconductors are a second example of the importance of textures in ceramics. In $\mathrm{YBa}_{2} \mathrm{Cu}_{3} \mathrm{O}_{7-x}$, for instance, the critical field is extremely anisotropic as shown in Fig.27. ${ }^{40}$ This material must be applied therefore with the direction of the electric current in the basal plane $a-b$. The most rigorous way how this can be achieved is to use single crystals, e.g. mono-crystalline films deposited on an appropriate substrate. ${ }^{41}$ Such films may grow truely monocrystalline (on a monocrystalline substrate) or with only basal plane orientation, i.e. with a strong c-axis fibre texture. Since the in-plane anisotropy in these materials is much smaller than the normal anisotropy shown in Fig. 27 a strong fibre texture is similar to a monocrystal except for the influence of grain boundaries. The fibre texture has a quite different MODF, eq.9, compared with a virtually monocrystalline layer.

The production of moncrystalline layers is the most efficient way, but at the same time it is also the most expensive way of orienting $H T_{c}$-superconducting materials. Much effort has therefore been devoted to producing highly oriented samples using true polycrystal methods such as powder deformation and sintering, ${ }^{42,43}$ electrophoresis ${ }^{44}$ or magnetic alignment ${ }^{45}$ of powder particles. Also directional solidification from the melt seems to be a promising me thod. ${ }^{46,47}$ Fig. 28 shows the ODF calculated from pole figures of magnetically aligned $\mathrm{YBa}_{2} \mathrm{Cu}_{3} \mathrm{O}_{7-x}$ powder. The maximum orientation density reaches a value of $\approx 30$ times random. This is already a strong texture jugded by standards usual in metals. Because of the extreme anisotropy, Fig.27, however, this texture is not yet strong enough. Besides this, the material showed a rather strong porosity so that is was unsuitable for technological application. Fig.28 illustrates three "levels" of texture investigation used in this materials i.e.

1. Comparison of peak-heights in the $2 \vartheta$-diagram.

2. Measurement of pole figures.

3. Calculation of ODF from pole figures.

Many texture studies in $H T_{c}$-superconductors have only used the first "level". This is sufficient to distinguish a very sharp basal- 


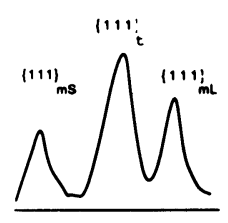

$\stackrel{2 \theta}{-}$
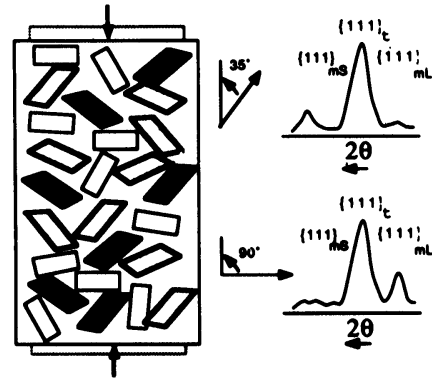

(b)

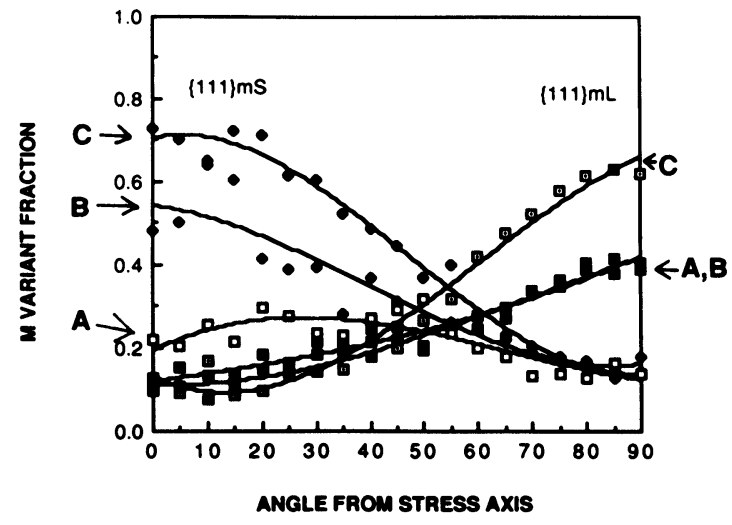

Fig.30 Ferroelectric polarization in $\mathrm{BaTiO}_{3}{ }^{49}$
Fig.29 Texture formation by phase transformation in $\mathrm{ZrO}_{2}{ }^{48}$

a) Transformation from tetragonal to monoclinic.

b) Diffraction peaks of the two phases.

c) Pole figures.
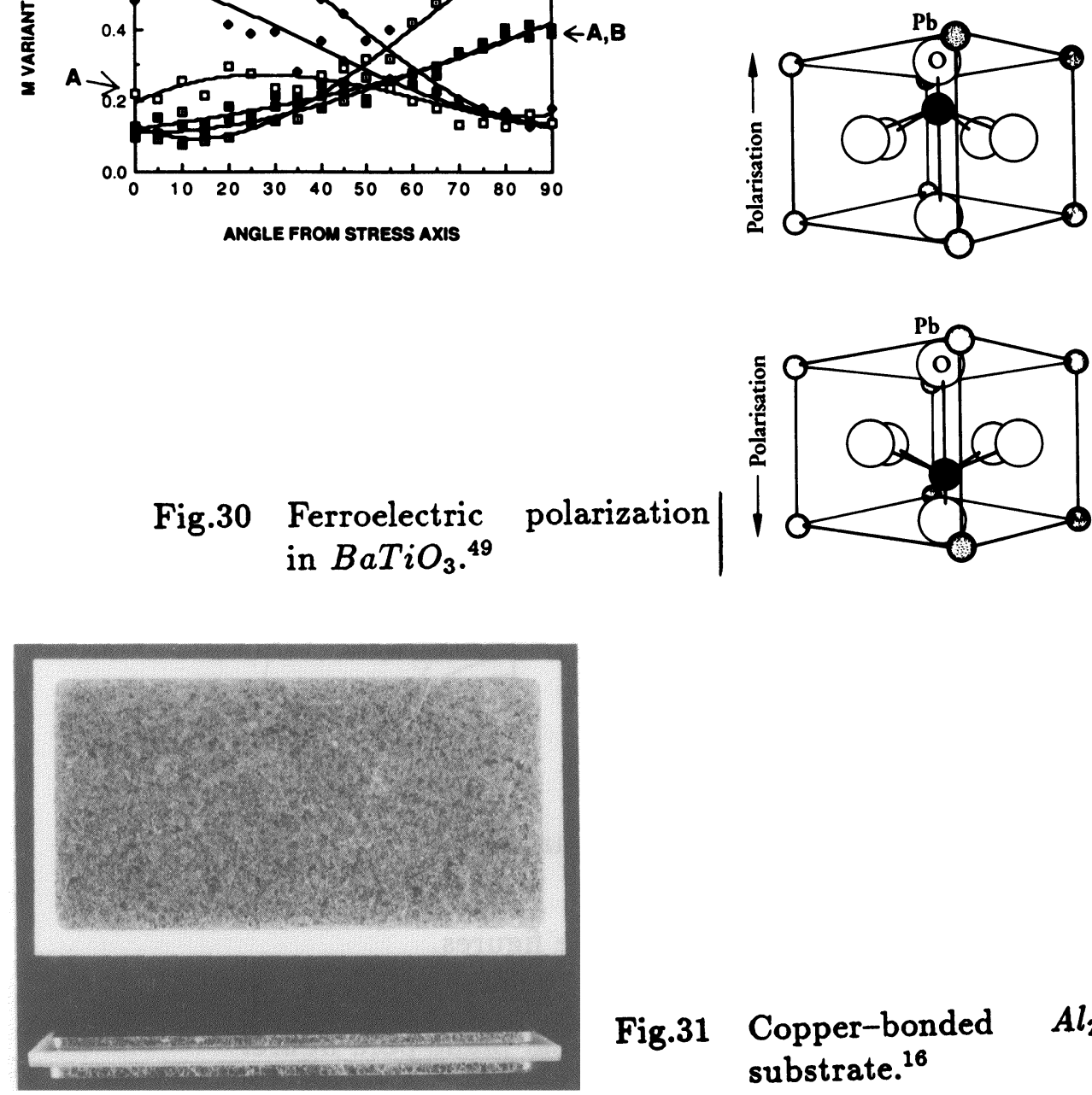

Fig.31 Copper-bonded $\mathrm{Al}_{2} \mathrm{O}_{3}$ substrate. ${ }^{16}$ 

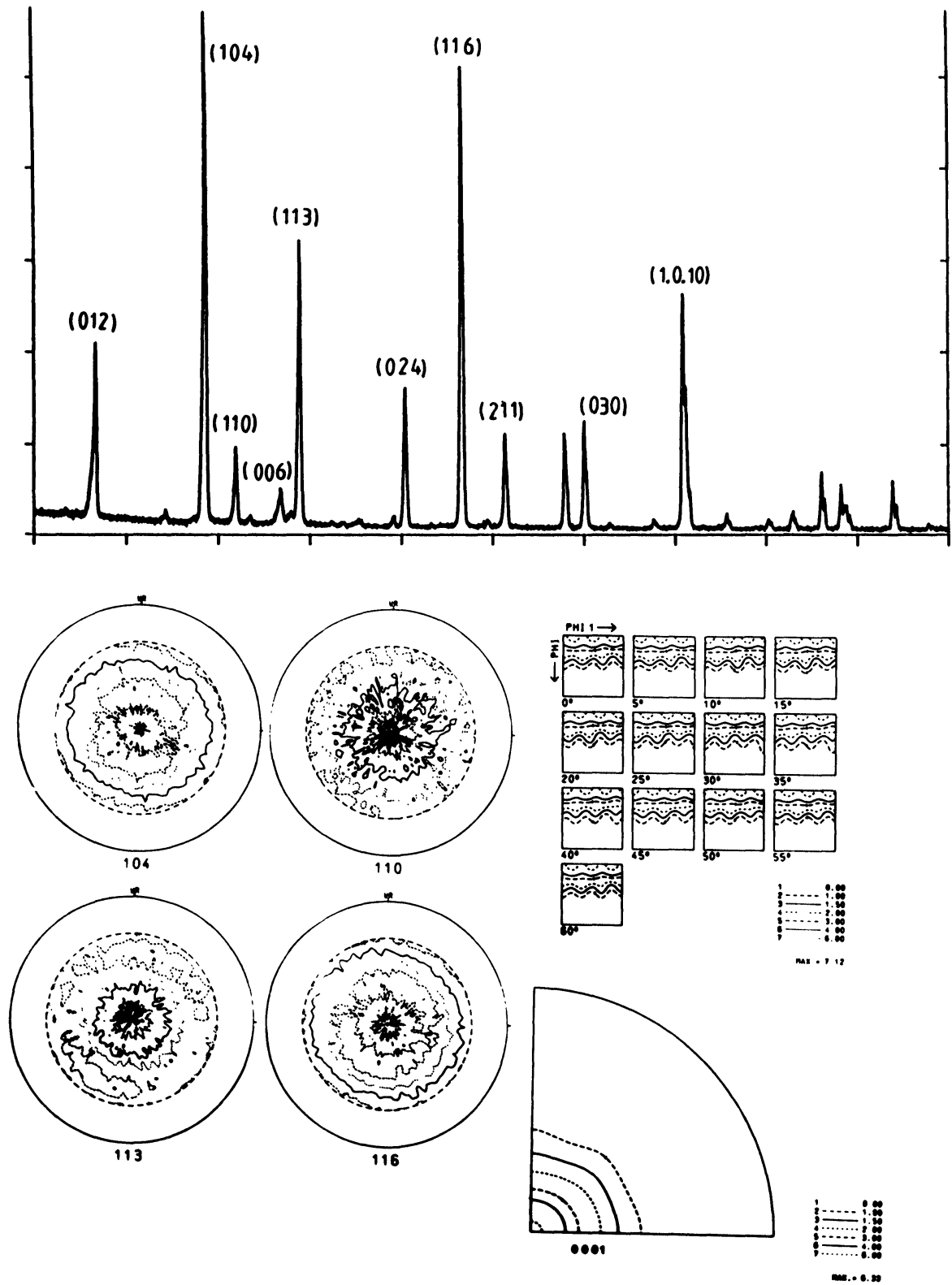

Fig.32 Texture determination in $\mathrm{Al}_{2} \mathrm{O}_{3}$.

a) $2 \vartheta$-diagram.

b) Measured pole figures.

c) ODF.

d) Recalculed basal plane pole figure. 
plane texture from virtually random distribution. The second "level" gives already much more information about the texture. It suffers, however, from abundant peak superposition in these materials which can only be resolved by using the third "level" i.e. the ODF.

Zirconium oxide $\mathrm{ZrO}_{2}$ is another "high-tech" ceramic material in which textures play an important role. The high toughness of this material is due to a phase transformation from a tetragonal to a monoclinic phase. This transformation is martensitic with a definit orientation relationship between the two phases. The higher symmetry of the tetragonal phase gives rise to several symmetry-equivalent transformation "variants" which are being chosen in such a way that their related shape change follows the applied stress. This is the reason for the toughness of the material. Hence, phase transformation gives rise to a texture transformation which depends on the direction of the applied stress as is shown in Fig. $29 .{ }^{48}$ Furthermore, the amount of shape change (and hence the toughening capacity) depends on the texture of the tetragonal phase which should be properly adapted to the direction of the occurring stresses.

Ferroelectric materials are another class of ceramics with strongly anisotropic properties, e.g. in $\mathrm{BaTiO}_{3}$ and others. Fig.30 shows the principles of the polarisation process. ${ }^{49}$ The magnitude of the ferroelectric effect is thus strongly anisotropic in the monocrystals and hence it depends on the texture in polycrystalline material. Table 4 gives, for example, the anisotropies of several ferroelectric properties of textured lead niobate. ${ }^{50}$ The development of texture in $\mathrm{Ba}$-titanate was studied, for instance, by pole figure measurement after high temperature plastic deformation. ${ }^{51,52}$

Aluminium oxide is one of the most important structural ceramics. Anisotropy of mechanical properties was found to be essential in $\mathrm{Al}_{2} \mathrm{O}_{3}$ substrates which are copper bonded on both sides (Fig. 31). Compounds of this type are exposed to thermal cycling for example in the range between $120^{\circ} \mathrm{C}$ and room temperature. After a certain number of cycles this leads to fracturing parallel to the substrate. It could be shown that this effect is closely related to the anisotropy of the material due to the texture of the substrate. This texture is however "camouflaged" as is explained in Fig.32: It turned out that the material develops a basal plane texture i.e. the hexagonal basal plane of the crystallites is preferrentially parallel to the plane of the 


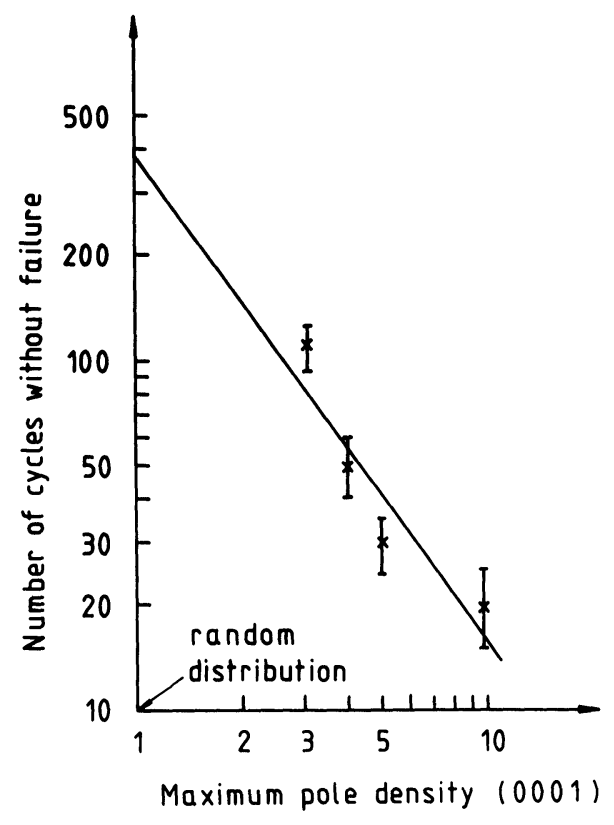

Fig.33 Fracturing resistance after thermal cycling as a function of preferred orientation. ${ }^{16}$

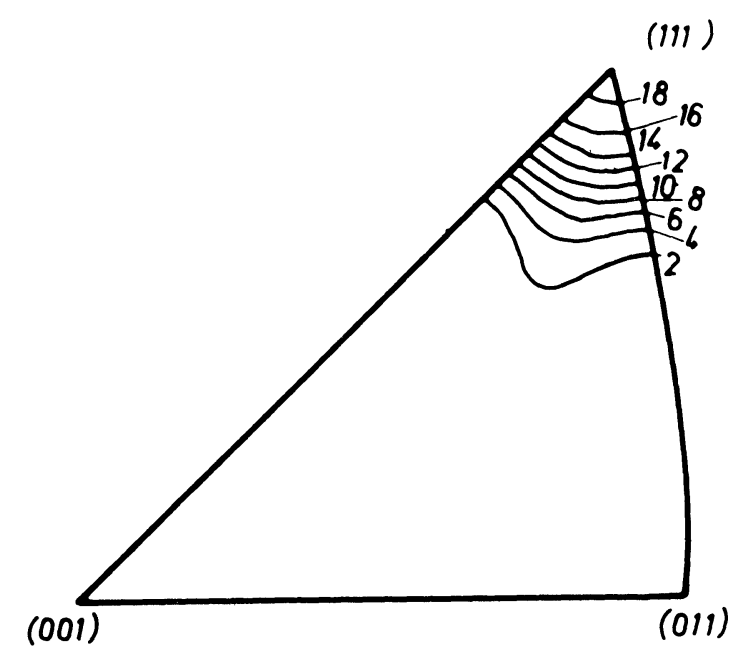

Fig.34 Orientation distribution function (inverse pole figure) of a $\mathrm{TiC}$ layer deposited on WC-substrates. ${ }^{54}$ 


\begin{tabular}{|c|ccc|l|}
\hline $\begin{array}{c}\text { Poling } \\
\text { Direction }\end{array}$ & $\mathrm{X}$ & Measuring direction & \\
\hline $\mathrm{X}$ & 340 & $\mathrm{Y}$ & $\mathrm{Z}$ & \\
$\mathrm{Y}$ & - & - & 310 & relative \\
$\mathrm{Z}$ & 390 & 410 & 320 & permittivity \\
\hline $\mathrm{X}$ & 0.20 & - & 260 & \\
$\mathrm{Y}$ & - & 0.22 & 0.20 & coupling \\
$\mathrm{Z}$ & 0.23 & 0.29 & 0.24 & factor \\
\hline $\mathrm{X}$ & 19 & - & 0.33 & \\
$\mathrm{Y}$ & - & 25 & 25 & mechanical \\
$\mathrm{Z}$ & 26 & 20 & 24 & quality \\
$\mathrm{X}$ & 1850 & - & 20 & factor \\
$\mathrm{Y}$ & - & 1950 & 1450 & Frequency \\
$\mathrm{Z}$ & 1690 & 1670 & 1870 & Constant \\
\hline
\end{tabular}

Tab.4 Electrical properties of textured $\mathrm{PbNb}_{2} \mathrm{O}_{6}$

substrate. This type of texture can be best seen in the basal plane pole figure. The basis reflexions have, however, very low structure factors i.e. their reflected intensities are very low. The (0006) reflection is, for example, $<1 \%$ of the strongest peak in the diffraction diagram. The pole figures of the stronger reflexions, which can be easily measured, are flat, however, as is also seen in Fig.32. Judged by these pole figures the texture was classified as being weak. This is, however, not true as can be seen from the ODF calculated from the pole figures as well as from the (0006) pole figure which was "re"calculated from the ODF. The ODF and this latter pole figure reach maximum density values of ten times random (in some cases even up to 30). These are strong textures. The degree of the texture correlates with the number of thermal cycles which the substrate can stand without breaking. This is shown in Fig.33. ${ }^{16}$ The highly textured substrates have a much lower thermal resistance than those with flat textures. If this relationship can be extrapolated back then it should be possible to produce substrates with even higher thermal resistance. The physical mechanisms leading to texture formation in these material are, however, not yet fully understood. It has been 


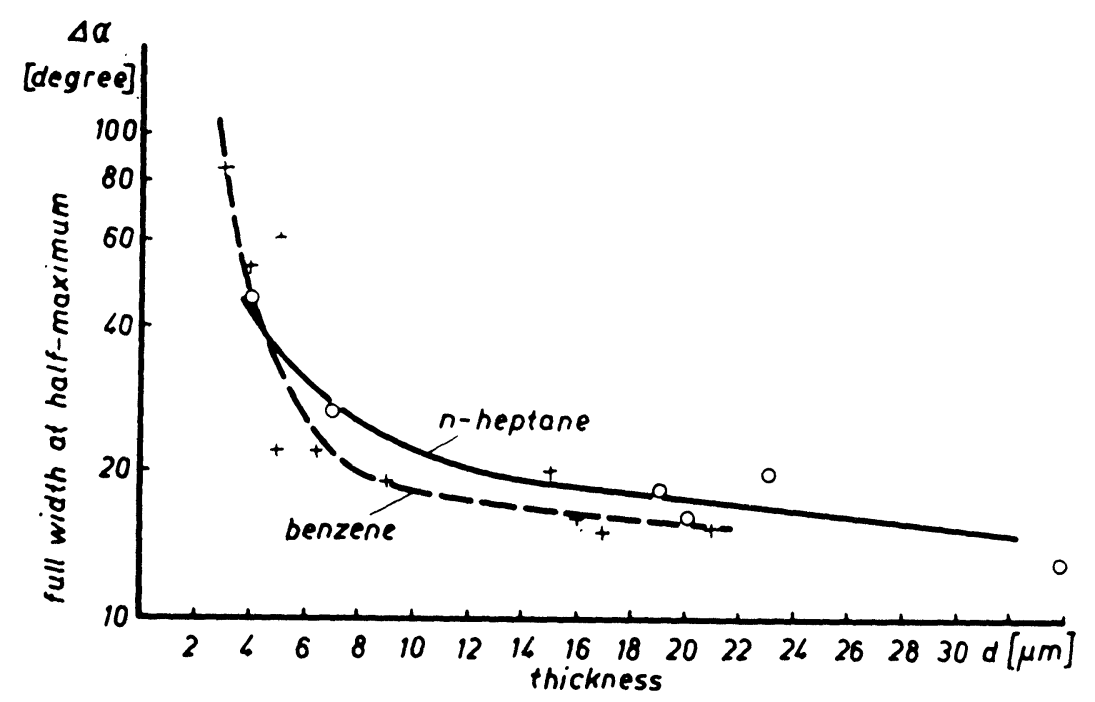

Fig.35 Dependence of the halfwidth of the (111) and (200) reflexion on the thickness of $\mathrm{TiC}$ layers on WC-substrates. ${ }^{54}$
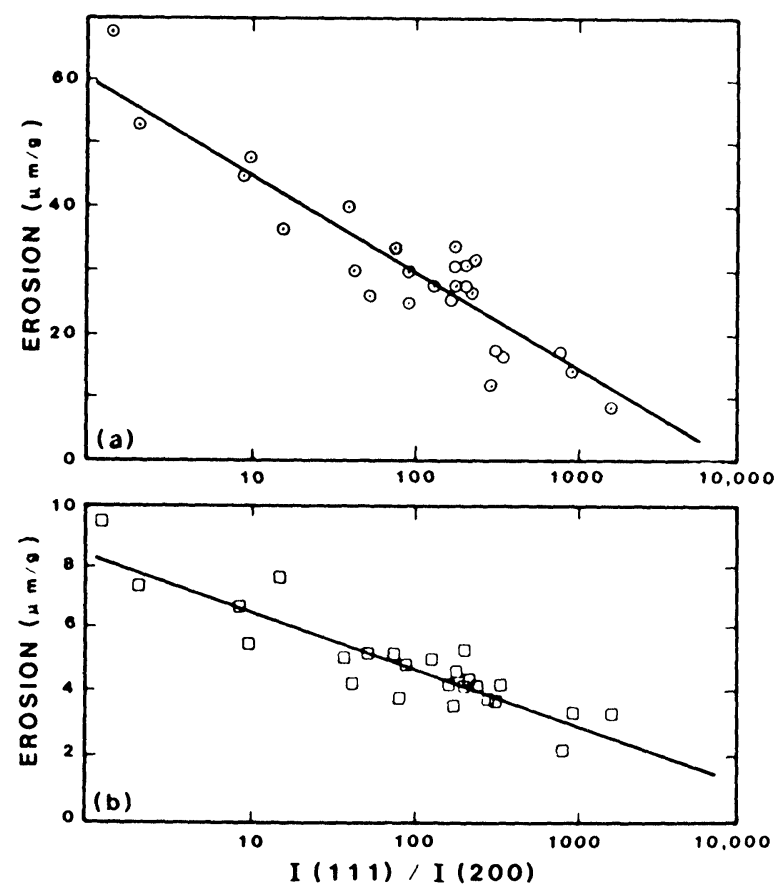

Fig.36 Alumina erosion rate of a TiN surface layer as a function of preferred orientation specified by the intensity ratio $\frac{I_{111}}{I_{200}} \cdot{ }^{55}$ 


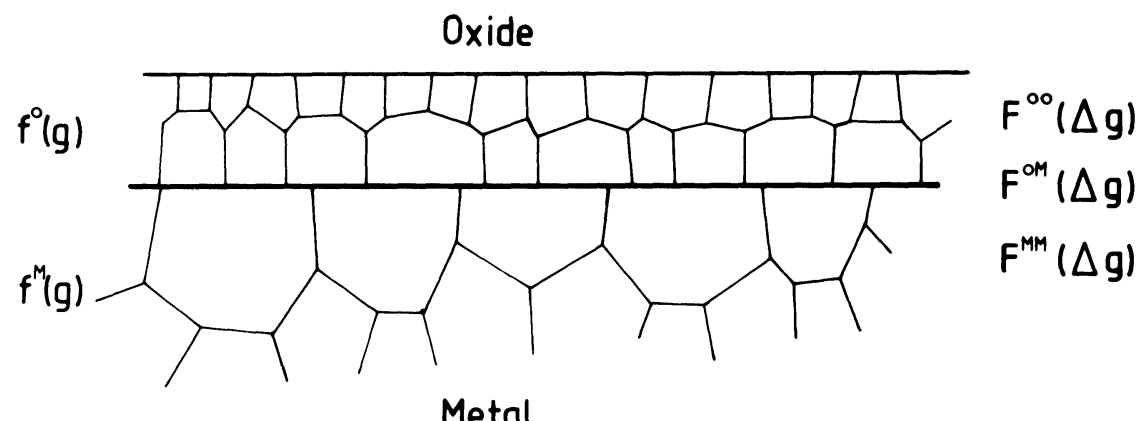

Metal

Fig.37 Schematic structure of an oxide scale on a metal surface. Both materials are characterized by their ODF, $\mathrm{f}(\mathrm{g})$, and MODF, $\mathrm{F}(\Delta \mathrm{g})$. The interface is characterized by the phase boundary MODF.

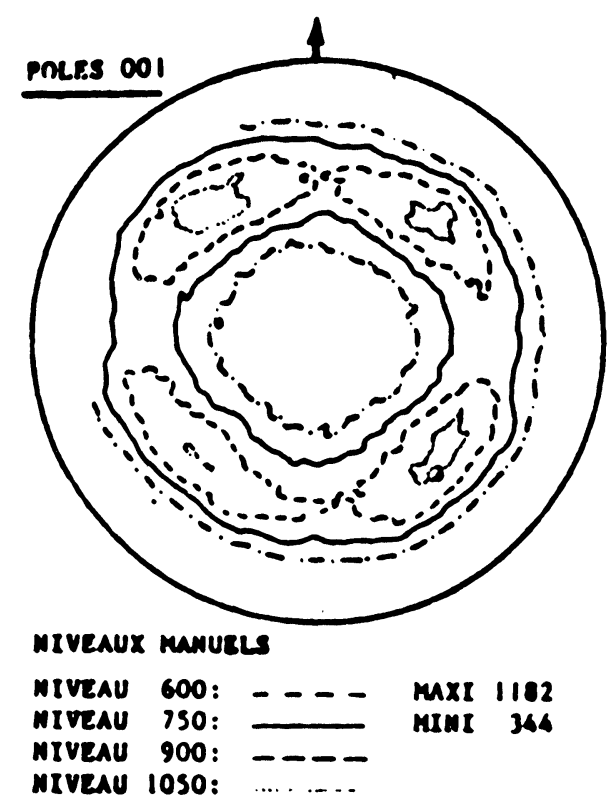

Fig.38 Pole figure (001) of $\mathrm{Nb}_{2} \mathrm{O}_{5}$ oxide scale on a niobium sheet. ${ }^{56,57}$ 


\begin{tabular}{|l|cc|}
\hline Material & $\perp \mathrm{c}$ & $\| \mathrm{c}\left[10^{6} /{ }^{\circ} \mathrm{C}\right]$ \\
\hline $\mathrm{Al}_{2} \mathrm{O}_{3}$ & 8.3 & 9.0 \\
$\mathrm{Al}_{2} \mathrm{TiO}_{5}$ & -2.6 & +11.5 \\
$3 \mathrm{Al}_{2} \mathrm{O}_{3} \cdot 2 \mathrm{SiO}_{2}$ & 4.5 & 5.7 \\
$\mathrm{TiO}_{2}$ & 6.8 & 8.3 \\
$\mathrm{ZrSiO}_{4}$ & 3.7 & 6.2 \\
$\mathrm{CaCO}_{3}$ & -6 & 25 \\
$\mathrm{SiO}_{2}$ (quartz) & 14 & 9 \\
$\mathrm{NaAlSi} \mathrm{O}_{8}$ (albite) & 4 & 13 \\
$\mathrm{C}$ (graphite) & 1 & 27 \\
\hline
\end{tabular}

Tab.5 Thermal expansion coefficients

found that the "green" foils have already a texture which is then modified strongly by the subsequent "firing" process. The physical reasons for the texture dependance shown in Fig.33 are also not yet fully understood. Model calculations indicate that the strongly textured substrates develop stronger thermal stresses during thermal cycling as a consequence of a greater difference in thermal expansion between copper and $\mathrm{Al}_{2} \mathrm{O}_{3}$. But also the anisotropy of cleavage (cleavage plane is the basal plane) must be taken into consideration.

The anisotropy of thermal expansion is a most important factor in many ceramic materials. Table 5 shows these values for some important materials. ${ }^{53}$ The values for aluminium titanate and calcium carbonate are to be emphasized here since they are negative in the basal plane. In these materials the texture described by the ODF and also the orientation correlation described by the MODF have a strong influence on the properties of polycrystalline samples.

Non-metallic coatings on metals are another special type of ceramics. As is shown, for instance in Fig.34, TiC-layers may develop a strong fibre texture which has in this case the (111)-plane parallel to the substrate plane. ${ }^{54}$ This texture was found to increase with increasing thickness of the layer as is seen in Fig.35 (but also decreasing texture sharpness has been observed with increasing layer thickness in other cases). The texture of the coating may have strong influence 


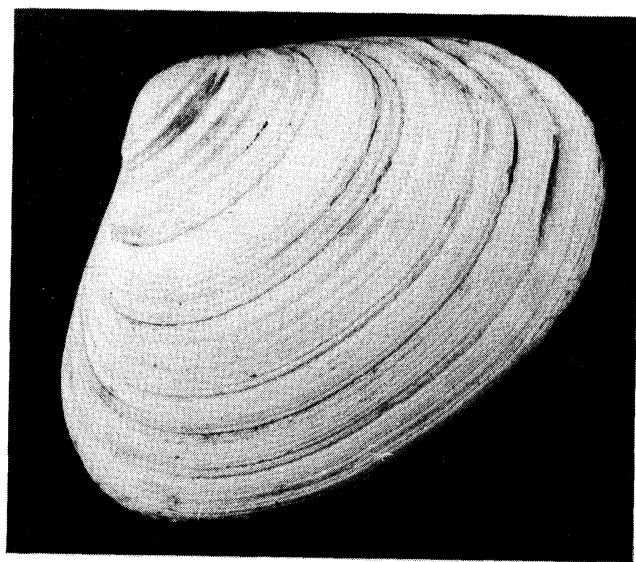

Fig.39 A sea shell.

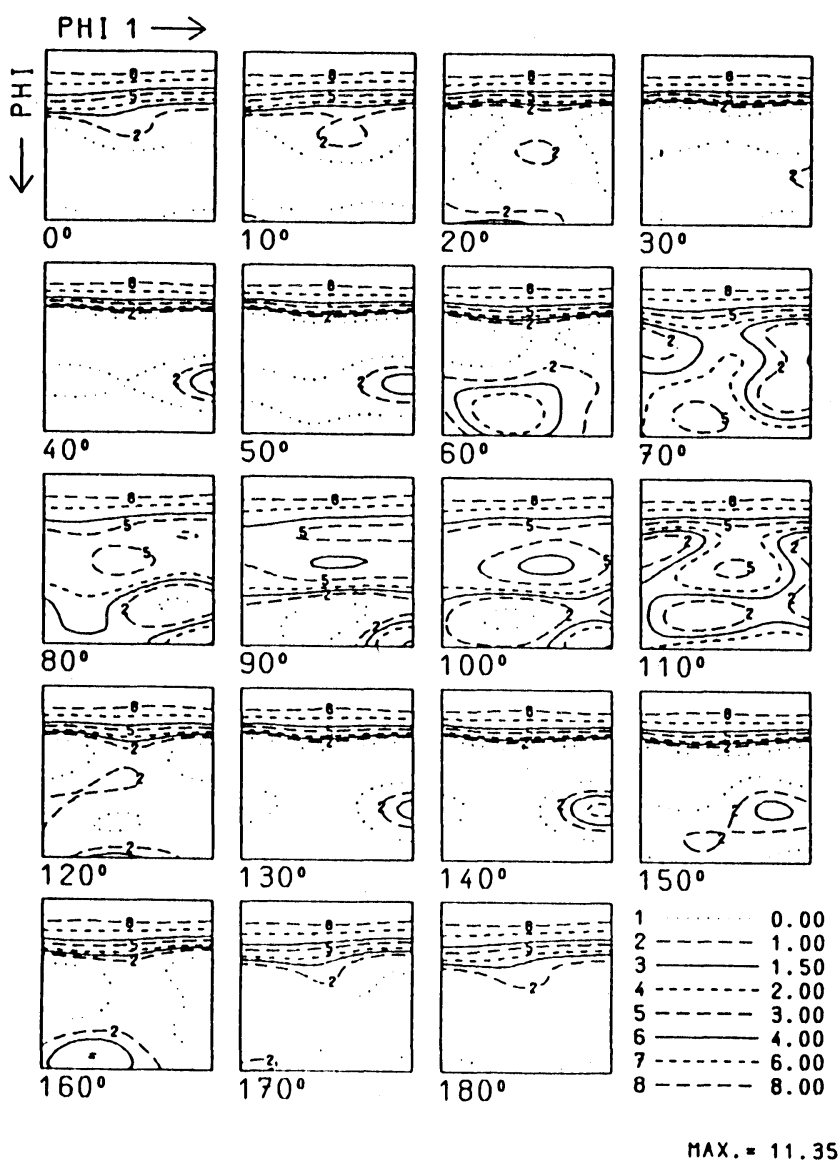

Fig.40 Texture of the sea shell of Fig.39. 
on the mechanical properties such as, for instance, erosion resistance as is shown in Fig.36 for TiN layers. ${ }^{55}$ In this category also oxide scales on metals have to be considered. Fig.37 shows schematically a polycrystalline oxide layer on a polycrystalline metal. The oxide layer grows on the metal by orientation dependent solid state processes. Hence the two textures $f^{O}(g)$ and $f^{M}(g)$ in Fig.37 will be related to each other. In order to understand the oxidation process, also the MODFs of the grain boundaries in both materials $F^{O O}(\Delta g)$ and $F^{M M}(\Delta g)$ are important. They have an influence on metal or oxygen diffusion. Finally, the phase boundary MODF $F^{O M}(\Delta g)$ will be related with the adhesive strength of the oxide layer. As an example, Fig.38 shows the (001)-pole figure of $\mathrm{Nb}_{2} \mathrm{O}_{5}$ on a Niobium sheet. ${ }^{56,57}$ It is seen that the orthorhombic sample symmetry of the substrate is inherited in the texture of the oxide layer by an oriented phase transformation process.

Sea shells, finally may be looked at as being "biological ceramics". Fig.39 shows a shell, consisting mainly of polycrystalline $\mathrm{CaCO}_{3}$. The texture of the shell is shown in Fig.40. The sample symmetry of the texture is orthorhombic indicating preferred orientation with respect to the shell plane as well as to a preferred direction in the plane.

\section{CONCLUSIONS}

- The texture of a polycrystalline material is defined independently of the nature of the material, i.e. metals, ceramics or polymers, by the orientation distribution function, ODF, of the crystallites.

- Textures are being formed by various physical processes such as primary crystallisation, plastic deformation, recrystallisation, phase transformation and rigid rotation. This is also quite similar in all kinds of materials.

- Finally, the texture is responsible for macroscopic anisotropies of those physical properties which are crystal anisotropic. Also this is quite similar in all kinds of polycrystalline materials. 
- Inspite of these similarities, texture studies, especially quantitative ones, were mostly done in the basic metals. This is mainly due to two reasons:

1. Experimental texture measurements and ODF calculation are more difficult in ceramics and polymers compared with the basic metals.

2. The influence of textures on the materials properties becomes the accuracy-limiting factor only if the influences of all other structural parameters are known and can be controlled quantitatively. This situation was reached earlier in metals than in non-metallic materials. Presently, non-metallic materials are attracting considerable interest from the technological point of view and, hence, also a considerable activity in fundamental research in these materials takes places. This is the reason for the increasing interest in texture studies in non-metallic materials in the last years. Simultaneously, improved experimental techniques and mathematical methods allow quantitative texture studies also in "difficult" materials: Among these methods the use of position sensitive detectors is to be mentioned as well as more sophisticated methods of pole figure inversion including the positivity of the distribution functions and ODF calculation from overlapped pole figures.

- Non-metallic materials mostly have lower crystal symmetries than the basic metals. Hence, the anisotropy of many of their physical properties is much stronger than in the case of metals. Hence, the influence of texture on the macroscopic properties of these materials is also stronger.

- In ceramic materials the grain shape texture can be defined additionally to the crystal lattice texture. If the grain shape is crystallographically controlled then grain shape texture and crystal lattice texture are related to each other.

- In polymers the chain texture can be defined for the crystalline and non-crystalline part. The chain texture of the crystalline part can be deduced uniquely from the crystal lattice texture. 
- As far as the anisotropy of physical properties is considered, the low-order coefficients of the series expansion, i.e. the loworder momenta of the distribution function are sufficient.

- In order to understand the physical process of texture formation the complete orientation distribution functions are necessary.

- All definitions of the texture, i.e. crystal lattice, grain shape, or chain texture, are defined independently of the positions of the crystallites (grains, or chains) in the polycrystalline material. They do not contain information about the orientation relationship of neighbouring "elements" in the material.

- The orientation relationship of neighbouring crystallites in polycrystals can be taken into consideration by the misorientation distribution function, MODF or by similarly defined orientation correlation functions. 


\section{REFERENCES}

[1] H.J. Bunge, Texture Analysis in Materials Science (Butterworths Publ. London 1982)

[2] H.J. Bunge, Intern. Materials Rev. 32265 (1987)

[3] H.J. Bunge, Directional Properties of Materials (DGM Informationgesellschaft Oberursel 1988) p.1

[4] H.J. Bunge, Beiträge zur Materialkunde (DGM Informationsgesellschaft Oberursel 1989) p.37

[5] H.J. Bunge, Z. Metallkunde $\underline{76}$, p.457 (1985)

[6] H.J. Bunge and H. Weiland, Textures and Microstructures 7 p.231 (1988)

[7] H.J. Bunge, Z. Metallkunde 76 p.92 (1985)

[8] P. Knipping, Physikalische Zeitschrift 14 p.996 (1913)

[9] G. Wassermann and J. Grewen, Texturen metallischer Werkstoffe (Springer, Berlin (1962))

[10] H.J. Bunge, Z. Metallkunde $\underline{56} 872$ (1965)

[11] R.J. Roe, J. Appl. Phys. $\underline{36}$ p.2024 (1965)

[12] H.J. Kopineck, Experimental Techniques of Texture Analysis (DGM Informationsgesellschaft, Oberursel 1986) p.171

[13] M. Dahms and H.J. Bunge, Experimental Techniques of Texture Analysis (DGM Informationgesllschaft, Oberursel 1986) p.371

[14] H. Stäblein and J. Wilbrand, IEEE Transactions on Magnetics Mag 2 p.459 (1966)

[15] H. Stäblein and J. Wilbrandt, Z. Angew. Physik 21 p.47 (1966)

[16] H. Klein, B. Waibel, W. Martin and H.J. Bunge, Joining Ceramics, Glass and Metals (DGM Informationsgesellschaft, Oberursel 1989) p.285

[17] J.J. Hermans, P.H. Hermans, D. Vermaas and A. Weidinger, Rec. Trav. Chim. Pays-Bas $\underline{65}$ p.427 (1946) 
[18] R.S. Stein, J. Polymer Sci. 31 p.327 (1958)

[19] Z.W. Wilchinski, J. Appl. Polymer Sci. 7 p.923 (1963)

[20] R.J. Roe and W.R. Krigbaum, J. Chem. Phys. 40 p.2608 (1964)

[21] W.R. Krigbaum and Y.I. Balta, J. Chem. Phys. $\underline{71}$ p.1770 (1967)

[22] W.R. Krigbaum, T. Adachi and J.V. Dawkins, J. Chem. Phys. $\underline{49}$ p.1532 (1968)

[23] J. Hirsch and P.T. Wang, Textures and Microstructures, in press

[24] B. Sander, Gefügeregelung der Gesteine. (Springer, Wien 1930)

[25] H.J. Bunge and H.R. Wenk, Tectonophysics $\underline{40}$ p.257 (1977)

[26] H.R. Wenk (Ed.) Preferred Orientation in Deformed Metals and Rocks: An Introduction to Modern Texture Analysis. (Academic Press, Orlando 1985)

[27] H.J. Bunge, H.R. Wenk and J. Pannetier, Textures and Microstructures $\underline{5}$ p.153 (1982)

[28] M. Dahms and H.J. Bunge, Theorical Methods of Texture Analysis (DGM Informationsgesellschaft, Oberursel 1987) p.143

[29] M. Dahms and H.J. Bunge, J. Appl.Cryst. 22 p.439 (1989)

[30] A.H. Heuer, D.J. Sellers and W.H. Rhodes, J. Amer. Ceramic Soc. 52 p.468 (1969)

[31] W.H. Rhodes, D.J. Sellers and T. Vasilos, J. Amer. Ceramic Soc. $\underline{58}$ p.31 (1975)

[32] G. Menges, Werkstoffkunde der Kunststoffe (Carl Hanser Verlag, München 1984)

[33] A.H. Windle, Developments in Oriented Polymers (Appl. Science Publ. London 1982) p.1

[34] F.J. Balta-Calleja and C.G. Vonk, X-ray Scattering of Synthetic Polymers (Elsevier Publ. Amsterdam 1989) 
[35] H.W. Spiess, Developments in Oriented Polymers (Appl. Sci. Publ. London 1982), p.47

[36] L. Monnerie, Developments in Oriented Polymers (Elsevier London 1987) p.199

[37] I.M. Ward, Developments in Oriented Polymers I (Applied Science Publishers London 1982)

[38] I.M. Ward, Developments in oriented Polymers II (Applied Science Publishers London 1987)

[39] H. Klein and H.J. Bunge, Textures and Microstructures (in preparation).

[40] L. Forro, J.Y. Henry, C. Ayache and P. Stamp, Physics Letters A 128 p.283 (1988)

[41] P.H. Kobrin, J.F. DeNatale, R.M. Housley, J.F. Flint, and A.B. Harker, Advanced Ceramic Materials 2 p.430 (1987)

[42] V.F. Shamray, High-Temperature Superconductors, Materials Aspects. (DGM Informationsgesellschaft, Oberursel 1990)

[43] K.A. Johnson, K.P. Staudhammer, W.J. Medina, C.B. Pierce and N.E. Elliott, Scripta Met. 22 p.1689 (1988)

[44] M. Hein, S. Kraut, G. Müller, D. Opie, H. Piel, L. Ponto and D. Wehler, High-temperature Superconductors Materials Aspects. (DGM Informationsgesellschaft, Oberursel 1990)

[45] W.P. Liu, N.J. Park and H.J. Bunge, Textures and Microstructures $\underline{13}$ p.41 (1990)

[46] Y. Yamada, C. Groth and R. Flückiger, High-Temperature Superconductors Materials Aspects. (DGM Informationsgesellschaft, Oberursel 1990)

[47] W. Knaak, High-temperature Superconductors Materials Aspects. (DGM Informationsgesellschaft, Oberursel 1990)

[48] K.J. Bowman, P.E. Reyes-Morel and I.W. Chen, Proc. 8-th. Intern. Conf. on Textures of Materials ICOTOM-8, (The Metallurgical Society, Warrendale 1988) p.811 
[49] J. Fricke, Physik in unserer Zeit 20 p.33 1989

[50] M. Granaham, M. Holmes, W.A. Schulze and R.E. Newnham, J. Amer. Ceramic Soc. 64 p.C-68 1981

[51] Y.J. Xia, X.W. Zhang, Z.G. Zhou, J. of Tsinghua University 23 p.11 (1983)

[52] V.S. Filipev, V.P. Zavyalov, O.A. Bunina, S.V. Gavrilyachenko and E.G. Fesenko, Sov. Phys. Tech. Phys. $\underline{29}$ p.374 (1984)

[53] W.D. Kingery, H.K. Bowen and D.R. Uhlmann, Introduction to Ceramics (John Wiley and Sons, New-York 1976)

[54] A. Leonhardt, D. Schläfer, M. Seidel, D. Selbmann and M. Schönherr, Journal of the Less Common Metals $\underline{87}$ p.63 (1982)

[55] J.A. Sue and H.H. Troue, Surface and Coating Technology $\underline{33}$ p.169 (1987)

[56] J.J. Heizmann, A. Vadon, C. Laruelle, L. Lattaud, D. Ciosmak and G. Bertrand, Proc. 8-th. Intern. Conf. on Textures of Materials ICOTOM-8 (The Metallurgical Society Warrendale 1988) p.789

[57] J.J. Heizmann, C. Laruelle, A. Vadon, C. Rousselet, D. Ciosmak and G. Bertrand, Proc. 8-th Intern. Conf. on Textures of Materials, ICOTOM-8, (The Metallurgical Society Warrendale 1988) p.783 